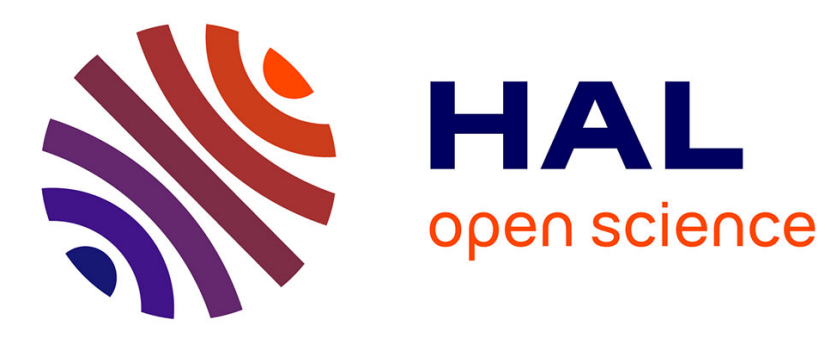

\title{
Sn-BEA zeolites prepared by two-step postsynthesis method: Physicochemical properties and catalytic activity in processes based on MPV reduction
}

Nataliia Popovych, Pavlo Kyriienko, Yannick Millot, Laetitia Valentin, Jacek

Gurgul, Robert Socha, Jan Żukrowski, Sergiy Soloviev, Stanislaw Dzwigaj

\section{To cite this version:}

Nataliia Popovych, Pavlo Kyriienko, Yannick Millot, Laetitia Valentin, Jacek Gurgul, et al.. Sn-BEA zeolites prepared by two-step postsynthesis method: Physicochemical properties and catalytic activity in processes based on MPV reduction. Microporous and Mesoporous Materials, 2018, 268, pp.178-188. 10.1016/j.micromeso.2018.04.026 . hal-01803945

\section{HAL Id: hal-01803945 \\ https://hal.sorbonne-universite.fr/hal-01803945}

Submitted on 20 Jul 2018

HAL is a multi-disciplinary open access archive for the deposit and dissemination of scientific research documents, whether they are published or not. The documents may come from teaching and research institutions in France or abroad, or from public or private research centers.
L'archive ouverte pluridisciplinaire HAL, est destinée au dépôt et à la diffusion de documents scientifiques de niveau recherche, publiés ou non, émanant des établissements d'enseignement et de recherche français ou étrangers, des laboratoires publics ou privés. 


\title{
Sn-BEA zeolites prepared by two-step postsynthesis method: Physicochemical properties and catalytic activity in processes based on MPV reduction
}

\author{
Nataliia O. Popovych ${ }^{\mathrm{a}}$, Pavlo I. Kyriienko ${ }^{\mathrm{a}, *}$, Yannick Millot ${ }^{\mathrm{b}}$, Laetitia Valentin ${ }^{\mathrm{b}}$, Jacek Gurgul ${ }^{\mathrm{c}}$, \\ Robert P. Socha ${ }^{c}$, Jan Żukrowski ${ }^{\mathrm{d}}$, Sergiy O. Soloviev ${ }^{\mathrm{a}}$, Stanislaw Dzwigaj ${ }^{\mathrm{b}, * *}$ \\ ${ }^{a}$ L.V.Pisarzhevskii Institute of Physical Chemistry, National Academy of Sciences of Ukraine, 31 Prosp. Nauky, 03028 Kyiv, Ukraine \\ b Sorbonne Université-CNRS, UMR 7197, Laboratoire de Réactivité de Surface, F-75005 Paris, France \\ ' Jerzy Haber Institute of Catalysis and Surface Chemistry, Polish Academy of Sciences, Niezapominajek 8, PL-30239 Kraków, Poland \\ ${ }^{\mathrm{d}}$ Academic Centre for Materials and Nanotechnology, AGH University of Science and Technology, PL-30-059 Kraków, Av. A. Mickiewicza 30, Poland
}

\begin{abstract}
A B S T R A C T
$\mathrm{Sn}_{0.5} \mathrm{SiBEA}$ and $\mathrm{Sn}_{2.0} \mathrm{SiBEA}$ zeolites obtained by two-step postsynthesis method were characterized by several physicochemical techniques (namely, NMR, Mössbauer, XPS, DR UV-vis and IR spectroscopies) and used in the study of Meerwein-Ponndorf-Verley (MPV) reduction as well as with the subsequent reaction of etherification, that is, conversion of (i) cyclohexanone with 2-propanol, (ii) 4-methoxybenzaldehyde with 2-butanol, and (iii) HMF with butyl alcohols (1-butanol, 2-butanol or isobutanol). The results have shown that in the case of cyclohexanone, MPV reduction to cyclohexanol occurs on both $\mathrm{Sn}_{0.5} \mathrm{SiBEA}$ and $\mathrm{Sn}_{2.0} \mathrm{SiBEA}$ zeolite catalysts with a higher degree of conversion in the presence of $\mathrm{Sn}_{2.0} \mathrm{SiBEA}$. For 4-methoxybenzaldehyde a tandem process was observed consisting of MPV reduction with 2-butanol to 4-methoxybenzylalcohol followed by its etherification with 2-butanol to 4-methoxybenzyl sec-butyl ether. Higher conversion of aldehyde was achieved on the catalyst with higher amount of tin. The zeolites were active in HMF conversion with butyl alcohols. However, a tandem process including MPV reduction with the next formation of furanic diether was achieved only in the presence of secondary alcohol at test conditions.
\end{abstract}

\section{Introduction}

Zeolites with isomorphically incorporated heteroelements are considered as promising catalysts for many processes of fine chemicals production and bio-resources conversion into valuable products in environmentally-friendly heterogeneous reactions alternatively to homogeneous [1,2]. Meerwein-Ponndorf-Verley (MPV) reduction of aldehydes and ketones to corresponding alcohols in organic synthesis is an important chemoselective reaction of hydrogen transfer, which results in carbonyl group reduction by aliphatic alcohols in the presence of other functional groups in a molecule (with multiple bonds, nitro groups etc) [3-5]. The use of zeolites with active centres of different nature will allow carrying out tandem processes, which include, in particular, MPV reduction of aldehydes followed by dehydration step synthesis of unsymmetrical ethers from aldehydes, conversion of furfural derivatives as products of primary processing of bio-resources [6-12].
Sn-BEA zeolites, obtained by direct synthesis in fluorine-containing medium, are studied as catalysts for such processes [7,10,13]. Industrial application of these zeolites will depend on the synthesis simplicity and zeolites cost. More simple and affordable two-step postsynthesis method developed earlier by Dzwigaj et al. [14] consists of Al removal from BEA zeolite framework by treatment with nitric acid and incorporation of Sn by reaction of tin precursor with silanol groups. Efficiency of Sn-BEA prepared by two-step postsynthesis method was shown earlier in the ring-opening hydration of epoxides [11], and 1,3dihydroxyacetone conversion to methyl lactate in methanol [15]. SnBEA activity will be determined to a great extent by state and position of tin in the zeolite framework.

In the present work, we have studied the effect of tin content in the dealuminated Sn-BEA zeolites, prepared by two-step postsynthesis method, on their physicochemical characteristics (state of tin sites and acidic properties) as well as on the catalytic properties in MPV reduction including processes with subsequent etherification.

\footnotetext{
* Corresponding author.

** Corresponding author.

E-mail addresses: pavlo_kyriienko@ukr.net (P.I. Kyriienko), stanislaw.dzwigaj@upmc.fr (S. Dzwigaj).
} 


\section{Experimental section}

\subsection{Materials}

Tetraethylammonium BEA (TEABEA) zeolite $(\mathrm{Si} / \mathrm{Al}=17)$ provided by RIPP (China) was dealuminated by a treatment with nitric acid solution of $\mathrm{C}=13 \mathrm{~mol} \mathrm{~L}^{-1}$ at $353 \mathrm{~K}$ for $4 \mathrm{~h}$, to obtain SiBEA zeolite with traces of $\mathrm{Al}$ and $\mathrm{Si} / \mathrm{Al}$ ratio of 1000 , and then it was washed several times with distilled water and dried at $368 \mathrm{~K}$ overnight. In the next step, two portions of SiBEA zeolite were contacted with $\mathrm{SnCl}_{4} \cdot 5 \mathrm{H}_{2} \mathrm{O}$ aqueous solution with appropriated concentration and stirred for $24 \mathrm{~h}$ at $298 \mathrm{~K}$. Then, the suspensions were stirred in evaporator under vacuum of a water pump for $2 \mathrm{~h}$ at $333 \mathrm{~K}$ until the water was evaporated. The resulting samples were dried in air at $383 \mathrm{~K}$ for $1 \mathrm{~h}$ and calcined in air at $873 \mathrm{~K}$ for $2 \mathrm{~h}$. The obtained materials were denoted as $\mathrm{Sn}_{\mathrm{x}} \mathrm{SiBEA}$ where subscript number next to element symbol refers to Sn wt \% content.

\subsection{Techniques}

X-ray powder diffraction (XRD) patterns of the catalysts were collected using an X'PERT PRO MPD diffractometer. $\mathrm{Cu} \mathrm{K}_{\alpha}$ radiation $(\lambda=1.54178 \AA)$, a graphite monochromator of the secondary beam (PW3122/00), and an X'CELERATOR detector were used. Measurements (at $40 \mathrm{kV}$ and $30 \mathrm{~mA}$ ) were performed in the $2 \theta$ range from $3^{\circ}$ to $75^{\circ}$ with interpolated step size of $0.02^{\circ}$.

The specific surface area and porosity of the $\mathrm{Sn}_{\mathrm{x}} \mathrm{SiBEA}$ zeolites were determined by low-temperature adsorption of nitrogen at $77 \mathrm{~K}$ using an Autosorb-1 Quantachrome apparatus. Prior to the measurements, the samples were preheated and degassed under vacuum at $393 \mathrm{~K}$ for $18 \mathrm{~h}$. Specific surface area of the samples was evaluated by Langmuir model, Brunauer-Emmett-Teller (BET) and t-plot methods (for relative pressures $\left(\mathrm{P} / \mathrm{P}_{0}\right)$ from 0.05 to 0.30$)$ and non-local density functional theory (NLDFT) with $\mathrm{N}_{2}$-silica model. Micropore volume was determined using t-plot method and mesopore volume was obtained by Barrett-JoynerHalenda method (desorption branches of isotherms).

${ }^{29} \mathrm{Si}$ Magic Angle Spinning (MAS) Nuclear Magnetic Resonance (NMR) spectra were recorded with a Bruker Avance500 spectrometer at $99.4 \mathrm{MHz}$ in $7 \mathrm{~mm}$ zirconia rotors. The chemical shifts of silicon were measured by reference to tetramethylsilane. ${ }^{29} \mathrm{Si}$ MAS NMR spectra were obtained at $7 \mathrm{kHz}$ spinning speed, $2.8 \mathrm{~s}$ excitation pulse and $10 \mathrm{~s}$ recycle delay. 3-(trimethylsilyl)-1-propanosulfonic sodium salt was used for setting the Hartmann-Hahn conditions. The proton 2 pulse duration, the contact time and recycle delay were $2.9 \mathrm{~s}, 5 \mathrm{~ms}$ and $5 \mathrm{~s}$, respectively.

${ }^{1} \mathrm{H}$ (MAS) NMR spectra were recorded with the Bruker Avance500 spectrometer at $500 \mathrm{MHz}$ with a $90^{\circ}$ pulse duration of $3 \mu$ s and a recycle delay of $5 \mathrm{~s}$. To record only the proton signal of the sample, the equipment for rotation $(12 \mathrm{kHz})$ was carefully cleaned with ethanol and dried in air at room temperature. The proton signals from probe and rotor were subtracted from the total free induction decay.

${ }^{27} \mathrm{Al}$ MAS NMR experiments were performed on a Bruker AVANCE500 spectrometer at $11.7 \mathrm{~T}$ in $4 \mathrm{~mm}$ zirconia rotors spinning at $14 \mathrm{kHz}$. The resonance frequency of ${ }^{27} \mathrm{Al}$ were $130.33 \mathrm{MHz}$, respectively. Chemical shifts, $\delta$, were reported relative to TMS and aqueous $\mathrm{Al}$ $\left(\mathrm{NO}_{3}\right)_{3} 1 \mathrm{~N}$ solution. ${ }^{27} \mathrm{Al}$ MAS NMR spectra were recorded by smallflip-angle technique with a pulse of $0.9 \mu s(\pi / 8), 0.5 \mathrm{~s}$ for the recycle delay and 2048 accumulations.

${ }^{119} \mathrm{Sn}$ NMR spectra were performed with a Bruker Avance500 spectrometer at $186.38 \mathrm{MHz}$ and with a $7 \mathrm{~mm}$ probe without spinning. For Static QCPMG experiment, the echo delay was set at $200 \mu \mathrm{s}, 51$ echoes were collected and we used a rf field strength of $62.5 \mathrm{kHz}$. The spikelet spectrum was obtained by direct Fourier transform of the echotrain. The reconstructed spectrum was produced by Fourier transform of sum of the individual echoes. Chemical shifts of tin were measured by reference to $\mathrm{SnO}_{2}(\delta=-604.0 \mathrm{ppm})$.

The ${ }^{119} \mathrm{Sn}$ Mössbauer measurements were conducted at room temperature in the transmission geometry using standard, constant acceleration Mössbauer spectrometer and a ${ }^{119} \mathrm{Sn}$ source in $\mathrm{CaSnO}_{3}$ matrix. The $23.88 \mathrm{keV} \gamma$-rays were detected with a $\mathrm{NaI}(\mathrm{Tl})$ scintillation counter. The spectrometer was calibrated with a $10-\mu \mathrm{m}$-thick $\alpha$-Fe foil. The surface density of the Mössbauer absorber was $55 \mathrm{mg} \mathrm{cm}^{-2}$. The Mössbauer spectra were analyzed numerically by fitting a hyperfine parameter distribution (HPD) using the Voigt-line-based method of Rancourt and Ping [16]. In this method, the HPD for a given crystal site corresponding to similar structural, chemical and magnetic properties is constructed by a sum of Gaussian components for the quadrupole splitting (QS) distributions and, if necessary, the magnetic hyperfine field $\mathrm{B}_{\mathrm{hf}}$ distributions. The isomer shift (IS) can be linearly coupled to the primary hyperfine parameters $\left(\mathrm{QS}, \mathrm{B}_{\mathrm{hf}}\right)$.

The X-ray Photoelectron Spectroscopy (XPS) measurements were carried out with a hemispherical analyzer (SES R4000, Gammadata Scienta). The unmonochromatized AlKa $(1486.6 \mathrm{eV}) \mathrm{X}$-ray source with the anode operating at $12 \mathrm{kV}$ and $15 \mathrm{~mA}$ current emission was applied to generate core excitation. The energy resolution of the system, measured as a full width at half maximum (FWHM) for $\mathrm{Ag} 3 \mathrm{~d}_{5 / 2}$ excitation line, was $0.9 \mathrm{eV}$ (pass energy $100 \mathrm{eV}$ ). The spectrometer was calibrated according to ISO 15472:2001. The base pressure in the analysis chamber was about $1 \times 10^{-10} \mathrm{mbar}$ and about $2 \times 10^{-9} \mathrm{mbar}$ during the experiment.

The powder samples were pressed into indium foil and mounted on a special holder. The area of sample analysis was about $4 \mathrm{~mm}^{2}$ $(5 \times 0.8 \mathrm{~mm})$. All spectra were collected at pass energy of $100 \mathrm{eV}$ (with $25 \mathrm{meV}$ step) except survey scans which were collected at pass energy of $200 \mathrm{eV}$ (with $0.25 \mathrm{eV}$ step). Intensities were estimated by calculating the integral of each peak (CasaXPS 2.3.15), after subtraction of the Shirley-type background, and fitting the experimental curve with a combination of Gaussian and Lorentzian lines of variable proportions (70: 30). The samples were weak conductive, thus all binding energy values were charge-corrected to the carbon $\mathrm{C} 1 \mathrm{~s}$ excitation, which set at $285.0 \mathrm{eV}$.

DR UV-vis spectra were recorded under ambient conditions on Specord M40 (Carl Zeiss) with a standard diffuse reflectance unit.

Analysis of the acidic properties of samples was performed by adsorption of pyridine (Py), $\mathrm{CD}_{3} \mathrm{CN}$ and $\mathrm{CO}$ followed by infrared spectroscopy (IR). Before analysis, the samples were pressed at $\sim 1$ ton $\mathrm{cm}^{-2}$ into thin wafers of ca. $10 \mathrm{mg} \mathrm{cm}^{-2}$ and placed inside the IR cell.

Before pyridine and $\mathrm{CD}_{3} \mathrm{CN}$ adsorption/desorption experiments, the wafers were activated by calcination in static conditions at $773 \mathrm{~K}$ for $1 \mathrm{~h}$ in $\mathrm{O}_{2}\left(2 \times 10^{4} \mathrm{~Pa}\right)$ and then outgassing under secondary vacuum at $673 \mathrm{~K}\left(10^{-3} \mathrm{~Pa}\right)$ for $1 \mathrm{~h}$. These wafers were contacted at $423 \mathrm{~K}$ with gaseous pyridine and at $298 \mathrm{~K}$ with $\mathrm{CD}_{3} \mathrm{CN}$. The spectra were recorded after desorption under vacuum at 423, 523 and $623 \mathrm{~K}$ (pyridine) and $298 \mathrm{~K}\left(\mathrm{CD}_{3} \mathrm{CN}\right)$ using a Spectrum One FT-IR spectrometer (resolution $1 \mathrm{~cm}^{-1}, 24$ scans). Concentration of Lewis acidic sites (LAS) was quantified based on desorption of pyridine at $423 \mathrm{~K}$ with integrated molar extinction coefficient $\varepsilon=1.42 \pm 0.30 \mathrm{~cm} / \mu \mathrm{mol}$ for IR peak at $1450 \mathrm{~cm}^{-1}$ of pyridine bounded to tin [17].

Before $\mathrm{CO}$ adsorption experiment, the wafers were activated by calcination at $723 \mathrm{~K}$ for $2 \mathrm{~h}$ in flowing $2.5 \% \mathrm{O}_{2} / \mathrm{Ar}\left(50 \mathrm{~mL} \mathrm{~min}^{-1}\right)$ and then outgassed at $573 \mathrm{~K}\left(10^{-3} \mathrm{~Pa}\right)$ for $1 \mathrm{~h}$. Following thermal treatment, the samples were cooled down to $100 \mathrm{~K}$. CO was introduced in increasing amounts up to an equilibrium pressure of $133 \mathrm{~Pa}$. Infrared spectra were recorded using a Bruker Vertex 70 FT-IR spectrometer (resolution $2 \mathrm{~cm}^{-1}, 64$ scans). The spectra were obtained after subtraction of the spectrum recorded after calcination and prior to $\mathrm{CO}$ adsorption. The contribution of $\mathrm{CO}$ in the gas phase was removed by subtraction of the gas-phase spectrum.

\subsection{Catalytic tests}

Zeolite catalyst $(50 \mathrm{mg}$ ) after activation $(873 \mathrm{~K}, 2 \mathrm{~h}$ ) was added to 
stock solution in a glass reactor. The stock solution (I) contained $1.23 \mathrm{mmol}$ of 4-methoxybenzaldehyde in 2-butanol (3.80 g) and stock solution (II) consisted of $1.18 \mathrm{mmol}$ of cyclohexanone in 2-propanol $(3.75 \mathrm{~g})$. Mesitylene was used as internal standard for chromatographic analysis. The reaction mixture was heated to $368 \mathrm{~K}$ with vigorous stirring. Aliquots were taken from the reaction mixture at various time intervals and analyzed after separation of the catalyst by centrifugation. The progress of the reaction was analyzed by gas chromatograph (KristalLyuks 4000M, MetaChrom, Russia) equipped with FID detector and HP-FFAP capillary column. The reactants and products were identified based on the coincidence of retention times with those of extra pure standards.

Reactions with HMF were carried out in a glass reactor, which was loaded with $50 \mathrm{mg}$ of zeolite catalyst after activation $(873 \mathrm{~K}, 2 \mathrm{~h})$, $1.25 \mathrm{mmol}$ of HMF, $3.80 \mathrm{~g}$ of butyl alcohol (1-butanol, 2-butanol or isobutanol) and the internal standard (mesitylene). The reactor was heated to the reaction temperature $(368 \mathrm{~K})$ in a glycerine bath and mixing was accomplished with a magnetic stirrer. After reaction $(8 \mathrm{~h})$, the reactor was cooled down and the products were analyzed after separation of the catalyst by centrifugation. The products were identified and quantified with HPLC (Agilent 1260 equipped with a diode-array detector, Kromasil C18 column $125 \times 3 \mathrm{~mm}, 5 \mu \mathrm{m}$ ) by creating a calibration curve with use of standard solutions, and confirmed by ${ }^{1} \mathrm{H}$ and ${ }^{13} \mathrm{C}$ NMR spectroscopy (Bruker Avance II ${ }^{\mathrm{TM}} 400 \mathrm{MHz}$ with CP-MAS II). Details of HPLC and NMR analyses are shown in supplementary information.

The conversion of substrate $(C, \%)$ and selectivity of products $(S, \%)$ were calculated as follows:

$C=\frac{n_{S}^{0}-n_{S}}{n_{S}^{0}} \cdot 100$

$S=\frac{n_{p}}{n_{S}^{0}-n_{S}} \cdot 100$,

where $n_{S}^{0}$ is initial amount of substrate moles, $n_{S}$ and $n_{p}$ are the amounts of substrate and product moles in the reaction products.

Turnover frequency (TOF) was defined as the number of moles of substrate converted per initial hour and per moles of surface Lewis acidic sites. Turnover number (TON) was calculated as the number of moles of reacted substrate divided by number of moles of Sn or Lewis acidic sites.

\section{Results and discussion}

\subsection{Structural characterization}

SiBEA, $\mathrm{Sn}_{0.5} \mathrm{SiBEA}$ and $\mathrm{Sn}_{2.0} \mathrm{SiBEA}$ present similar powder XRD patterns, typical for BEA zeolite (Fig. 1). Crystallinity of BEA zeolite is preserved after dealumination and introduction of tin ions in SiBEA. Additional peaks due to crystalline $\mathrm{SnO}_{2}$ or any other crystalline impurity phases were not detected. Increase in $\mathrm{d}_{302}$ spacing from $3.920 \AA$ (SiBEA; $\left.2 \theta=22.67^{\circ}\right)$ to $3.936\left(\mathrm{Sn}_{0.5} \operatorname{SiBEA} ; 2 \theta=22.57^{\circ}\right)$ and $3.926 \AA$ $\left(\mathrm{Sn}_{2.0} \mathrm{SiBEA} ; 2 \theta=22.63^{\circ}\right)$ observed after incorporation of $\mathrm{Sn}$ into SiBEA points out its expansion due to longer Sn-O bond length $(1.91 \AA$ [10]) compared to Si-O (typically 1.60-1.65 A in zeolites [18]).

The textural properties of $\mathrm{Sn}_{0.5} \mathrm{SiBEA}$ and $\mathrm{Sn}_{2.0} \mathrm{SiBEA}$ were studied by low-temperature nitrogen sorption. All nitrogen adsorption and desorption isotherms (Fig. 2) are type I according to IUPAC. BET surface area in the range of $430-467 \mathrm{~m}^{2} \mathrm{~g}^{-1}$ and micropore volume of $0.18-0.20 \mathrm{~cm}^{3} \mathrm{~g}^{-1}$ (Table 1) are typical values reported for dealuminated BEA zeolites [19]. Higher surface area obtained by Langmuir and NLDFT models (e.g., 707 and $728 \mathrm{~m}^{2} \mathrm{~g}^{-1}$ for $\mathrm{Sn}_{0.5} \mathrm{SiBEA}$ ) may indicate that BET method applied on isotherms of microporous $\mathrm{Sn}_{\mathrm{x}} \mathrm{SiBEA}$ zeolites in "standard" relative pressure range underestimates the true internal surface area.

The similar specific surface areas and crystallinity for SiBEA [19]

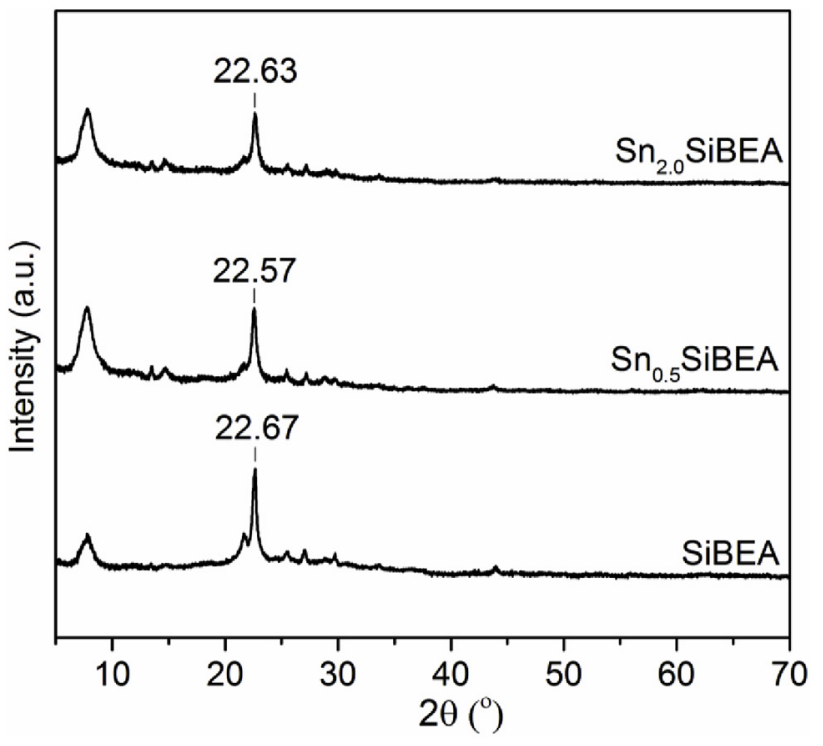

Fig. 1. X-ray diffractograms of SiBEA, $\mathrm{Sn}_{0.5} \mathrm{SiBEA}$ and $\mathrm{Sn}_{2.0} \mathrm{SiBEA}$ (calcined in flowing air at $873 \mathrm{~K}$ for $2 \mathrm{~h}$ ) recorded at room temperature and ambient atmosphere.

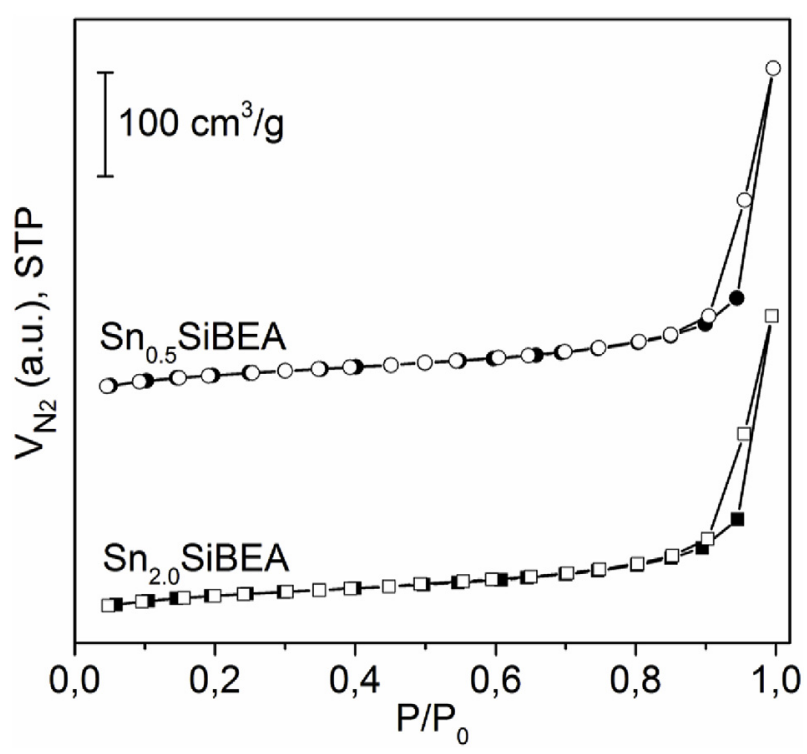

Fig. 2. Adsorption isotherms of nitrogen at $77 \mathrm{~K}$ for $\mathrm{Sn}_{0.5} \mathrm{SiBEA}$ and $\mathrm{Sn}_{2.0} \mathrm{SiBEA}$ (calcined in flowing air at $873 \mathrm{~K}$ for $2 \mathrm{~h}$ ) (for convenience, the datasets of $\mathrm{Sn}_{0.5}$ SiBEA were shifted upwards along the Y-axis).

Table 1

Textural properties of the zeolites.

\begin{tabular}{lllllll}
\hline Sample & $\begin{array}{l}\mathrm{S}_{\mathrm{BET}}, \\
\mathrm{m}^{2} \cdot \mathrm{g}^{-1}\end{array}$ & $\begin{array}{l}\mathrm{S}_{\text {Langmuir }}, \\
\mathrm{m}^{2} \cdot \mathrm{g}^{-1}\end{array}$ & $\begin{array}{l}\mathrm{S}_{\text {ext.(t- }} \\
\mathrm{plot}) \\
\mathrm{m}^{2} \cdot \mathrm{g}^{-1}\end{array}$ & $\begin{array}{l}\mathrm{S}_{\mathrm{NLDFT}}, \\
\mathrm{m}^{2} \cdot \mathrm{g}^{-1}\end{array}$ & $\begin{array}{l}\mathrm{V}_{\text {micro, }} \\
\mathrm{cm}^{3} \cdot \mathrm{g}^{-1}\end{array}$ & $\begin{array}{l}\mathrm{V}_{\text {meso }}, \\
\mathrm{cm}^{3} \cdot \mathrm{g}^{-1}\end{array}$ \\
\hline $\mathrm{Sn}_{0.5} \mathrm{SiBEA}$ & 467 & 707 & 109 & 728 & 0.20 & 0.51 \\
$\mathrm{Sn}_{2.0} \mathrm{SiBEA}$ & 430 & 670 & 103 & 684 & 0.18 & 0.47 \\
\hline
\end{tabular}

and $\mathrm{Sn}_{\mathrm{x}} \mathrm{SiBEA}$ as well as absence of extra-framework crystalline compounds or long-range amorphization indicate that tin is incorporated into the zeolite matrix as well dispersed species.

\subsection{Spectroscopic characterization}

The ${ }^{29} \mathrm{Si}$ direct polarization (DP) MAS NMR spectrum of SiBEA 

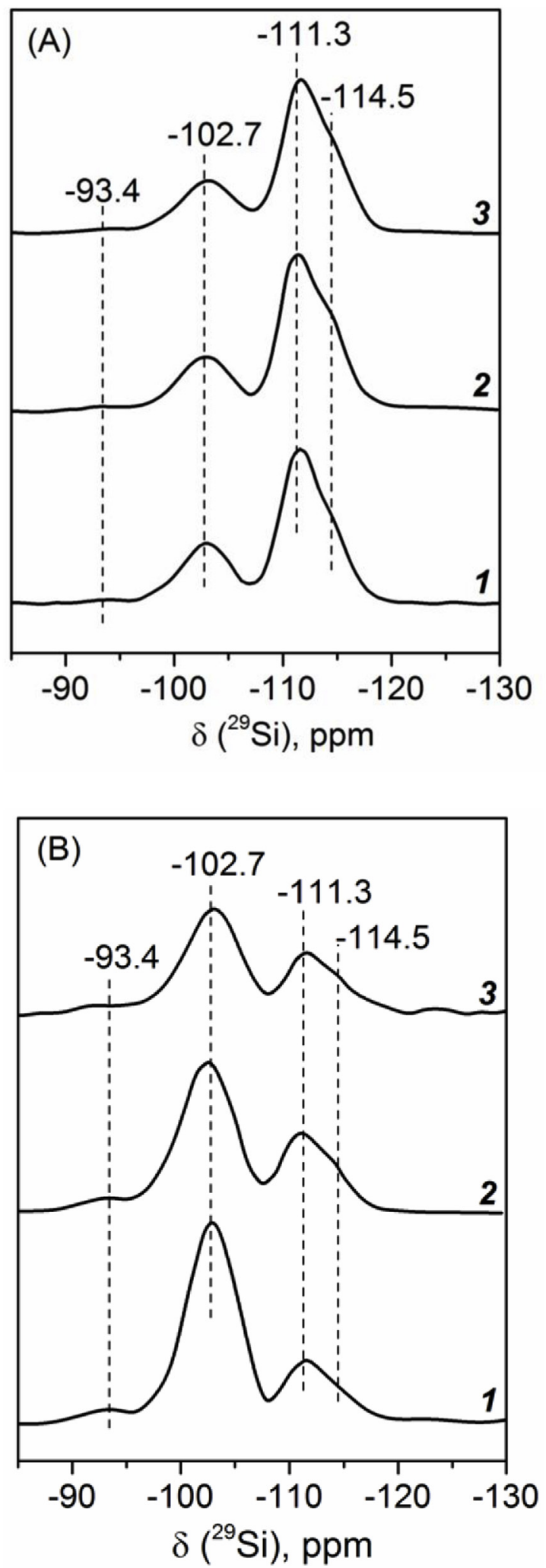

Fig. 3. ${ }^{29} \mathrm{Si}$ MAS NMR spectra recorded at room temperature of SiBEA (1), $\mathrm{Sn}_{0.5} \mathrm{SiBEA}(2)$ and $\mathrm{Sn}_{2.0} \mathrm{SiBEA}(3)$ (A - direct polarization, B - cross-polarization).

(Fig. 3 A) shows two peaks at -114.5 and $-111.3 \mathrm{ppm}$ due to framework $\mathrm{Si}$ atoms in a $\mathrm{Si}(\mathrm{OSi})_{4}\left(\mathrm{Q}^{4}\right)$ environment located at different crystallographic sites. A broad signal at $-102.7 \mathrm{ppm}$ is also observable and could be attributed to $Q^{3}$ species. The strong increase of intensity of

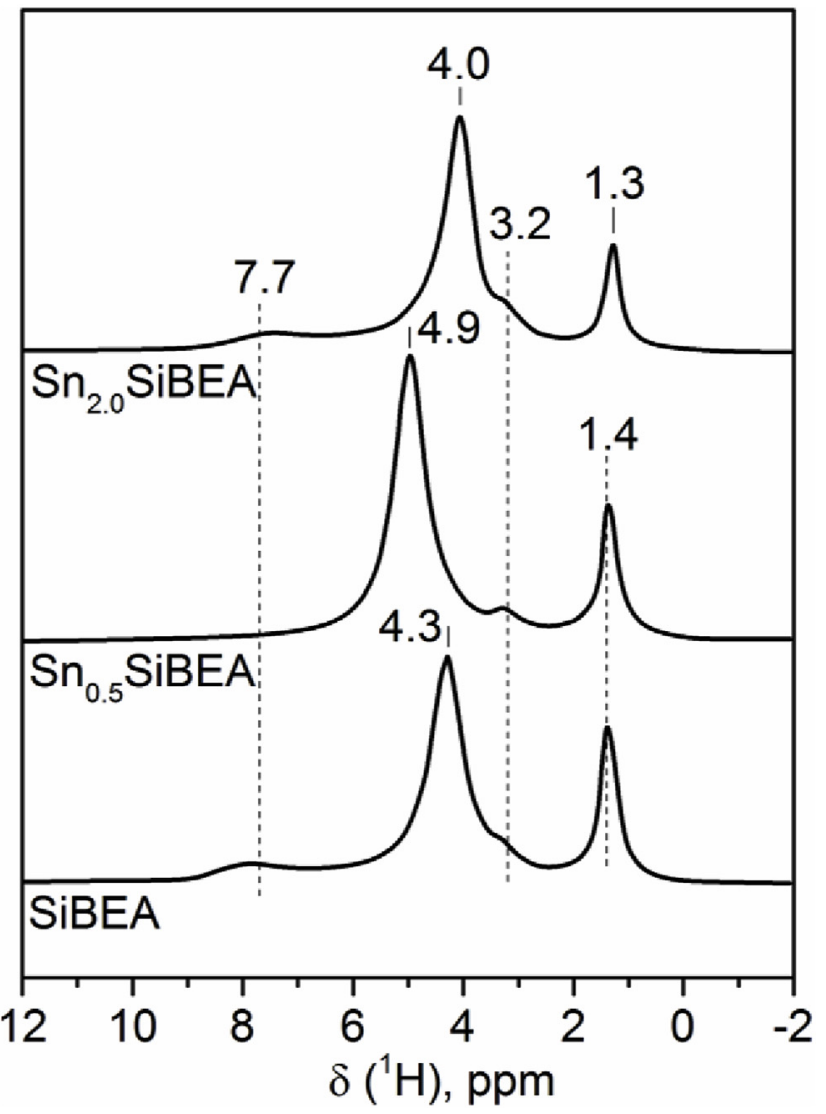

Fig. 4. ${ }^{1} \mathrm{H}$ MAS NMR spectra of $\mathrm{SiBEA}, \mathrm{Sn}_{0.5} \mathrm{SiBEA}$ and $\mathrm{Sn}_{2.0} \mathrm{SiBEA}$ recorded at room temperature in $4 \mathrm{~mm}$ (external diameter) zirconia rotor.

this peak by cross polarization (CP) MAS (Fig. 3 B) indicates that this signal is due to the $(\mathrm{OSi})_{3} \mathrm{Si}(\mathrm{OH})$ groups. In the same way, the new peak at $-93.4 \mathrm{ppm}$ in CPMAS experiment is attributed to $\mathrm{Q}^{2}$ species $\left((\mathrm{OSi})_{2} \mathrm{Si}(\mathrm{OH})_{2}\right)$.

The ${ }^{29} \mathrm{Si}$ DPMAS NMR spectra of $\mathrm{Sn}_{0.5} \mathrm{SiBEA}$ and $\mathrm{Sn}_{2.0} \mathrm{SiBEA}$ (Fig. 3 A) are constituted by the same two signals coming from $Q^{4}$ species $\left(-111.3\right.$ and $-114.5 \mathrm{ppm}$ ) but the signal coming from $\mathrm{Q}^{3}$ species is slightly reduced. This suggests that reaction between $\mathrm{SnCl}_{4}$ and $\mathrm{SiOH}$ groups leads to the appearance of pseudo-tetrahedral tin species in framework position. Such interpretation is corroborate by CPMAS experiment (Fig. 3 B), in which indeed, the cross polarization effect on the signal at $-102.7 \mathrm{ppm}$ is less important than for SiBEA, which means consumption of some $\mathrm{Si}-\mathrm{OH}$ groups.

In the ${ }^{1} \mathrm{H}$ MAS NMR spectrum of SiBEA two main peaks appear at 4.3 and $1.4 \mathrm{ppm}$ (Fig. 4), due to the protons of H-bonded Si-OH groups present at vacant $\mathrm{T}$-atom sites and isolated $\mathrm{Si}-\mathrm{OH}$ groups respectively, as earlier shown for different zeolites [20,21]. In addition, two small peaks at 7.7 and $3.2 \mathrm{ppm}$ appeared probably due to protons of water molecules and of $\mathrm{H}$-bonded $\mathrm{Si}-\mathrm{OH}$ groups located in a second type of crystallographic site, in line with earlier work [19].All above-mentioned peaks are also well visible in ${ }^{1} \mathrm{H}$ MAS NMR spectra of the $\mathrm{Sn}_{0.5} \mathrm{SiBEA}$ and $\mathrm{Sn}_{2.0} \mathrm{SiBEA}$ samples (Fig. 4). However, there is a small difference in the chemical shift of the most intense peak obtained in NMR spectra of $\mathrm{Sn}_{\mathrm{x}} \mathrm{SiBEA}$ and SiBEA. In $\mathrm{Sn}_{0.5} \mathrm{SiBEA}$ spectrum one can find this peak at $4.9 \mathrm{ppm}$, whereas in $\mathrm{Sn}_{2.0} \mathrm{SiBEA}$ spectrum its chemical shift is $4.0 \mathrm{ppm}$ (compare to that present in SiBEA at $4.3 \mathrm{ppm}$ ). It suggests that the protons of $\mathrm{H}$-bonded $\mathrm{SiOH}$ groups in vacant T-atom sites are in interaction with introduced tin species. The difference between both samples, $\mathrm{Sn}_{0.5}$ SIBEA and $\mathrm{Sn}_{2.0}$ SIBEA, can come from the different amount of introduced tin and the existence of various tin species in zeolite matrix. 


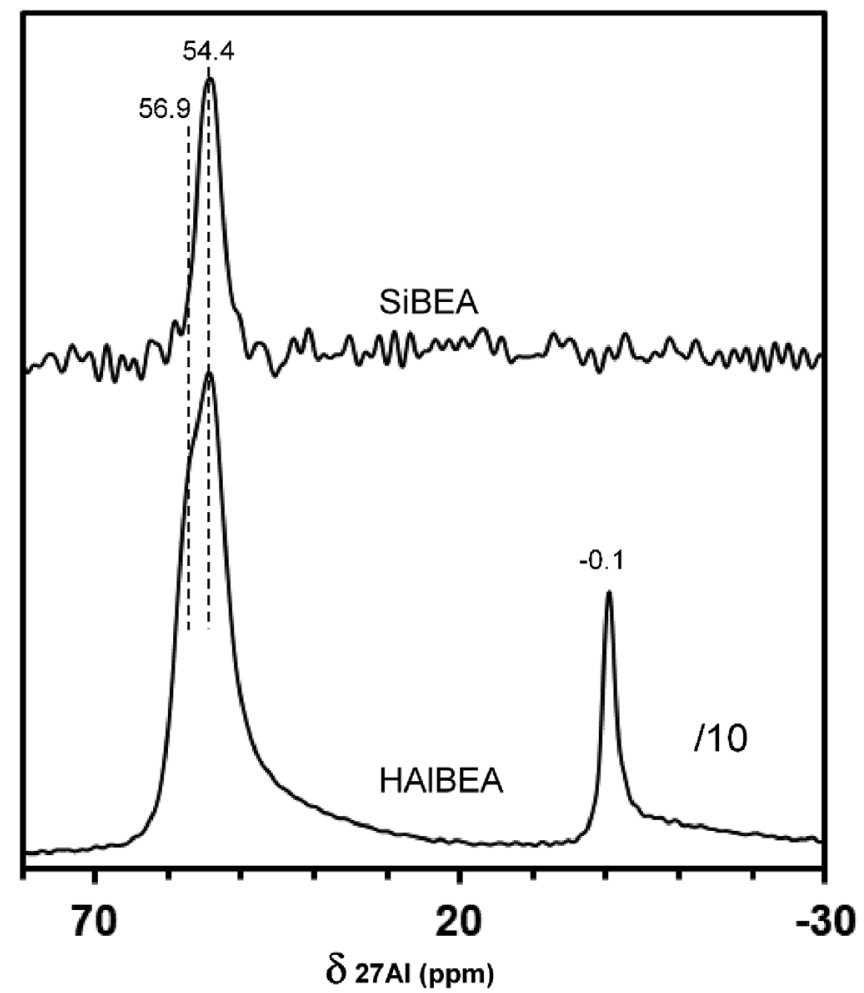

Fig. 5. ${ }^{27} \mathrm{Al}$ MAS NMR spectra of SiBEA and HAlBEA recorded at room temperature in $4 \mathrm{~mm}$ (external diameter) zirconia rotor.

The ${ }^{27} \mathrm{Al}$ NMR spectra of HAlBEA zeolite have 3 resonances and of SiBEA only one resonance (Fig. 5). The resonances at 56.9 and $54.4 \mathrm{ppm}$ in the spectrum of HAlBEA correspond to two types of framework aluminum atoms in the tetrahedral environment. The resonances at $-0.1 \mathrm{ppm}$ correspond to aluminum atoms in an octahedral environment. The ${ }^{27} \mathrm{Al}$ NMR spectra of the SiBEA zeolite (Fig. 5) have one very small contribution which corresponds to traces of aluminum present in SiBEA zeolite in the tetrahedral environment.

IR spectrum of SiBEA in Fig. 6 shows presence of different silanol groups. Bands at 3739,3709 and $3520 \mathrm{~cm}^{-1}$ are attributed to isolated internal, terminal internal and hydrogen bonded Si-OH, respectively, located in the vacant T-atom sites of the SiBEA framework. Upon introduction of $2.0 \mathrm{Sn}$ wt \% into SiBEA the decreased intensity of the bands at 3739,3709 and $3520 \mathrm{~cm}^{-1}$ indicates that some groups have been consumed during their reaction with tin precursor, however not all internal Si-OH groups are consumed and residual silanol nests remain in the zeolite structure.

\subsection{Characterization of tin sites}

Oxidation state and chemical environment of tin sites in the $\mathrm{Sn}_{0.5} \mathrm{SiBEA}$ and $\mathrm{Sn}_{2.0} \mathrm{SiBEA}$ zeolites were investigated by ${ }^{119} \mathrm{Sn}$ NMR, ${ }^{119} \mathrm{Sn}$ Mössbauer (MS), X-ray photoelectron and DR UV-vis spectroscopies.

${ }^{119} \mathrm{Sn}$ NMR spectra of hydrated and dehydrated $\mathrm{Sn}_{2.0}$ SiBEA are given in Fig. 7. For hydrated sample only one broad tin signal is detected around $-650 \mathrm{ppm}$ (Fig. 7(a)). This chemical shift is related to octahedral Sn(IV) species, present as major species in hydrated $\mathrm{Sn}_{2.0}$ SiBEA [22]. After dehydration, the ${ }^{119} \mathrm{Sn}$ NMR spectrum shows three well visible contributions at $-440,-590$ and $-715 \mathrm{ppm}$. The first one with chemical shift of $-440 \mathrm{ppm}$ could be attributed to isolated tetrahedral Sn(IV) present in the zeolite framework [23,24]. The other two signals ( -590 and $-715 \mathrm{ppm}$ ) could be assigned to distorted octahedral $\mathrm{Sn}(\mathrm{IV})$ species present in the extra-framework positions of zeolite BEA [23,25].

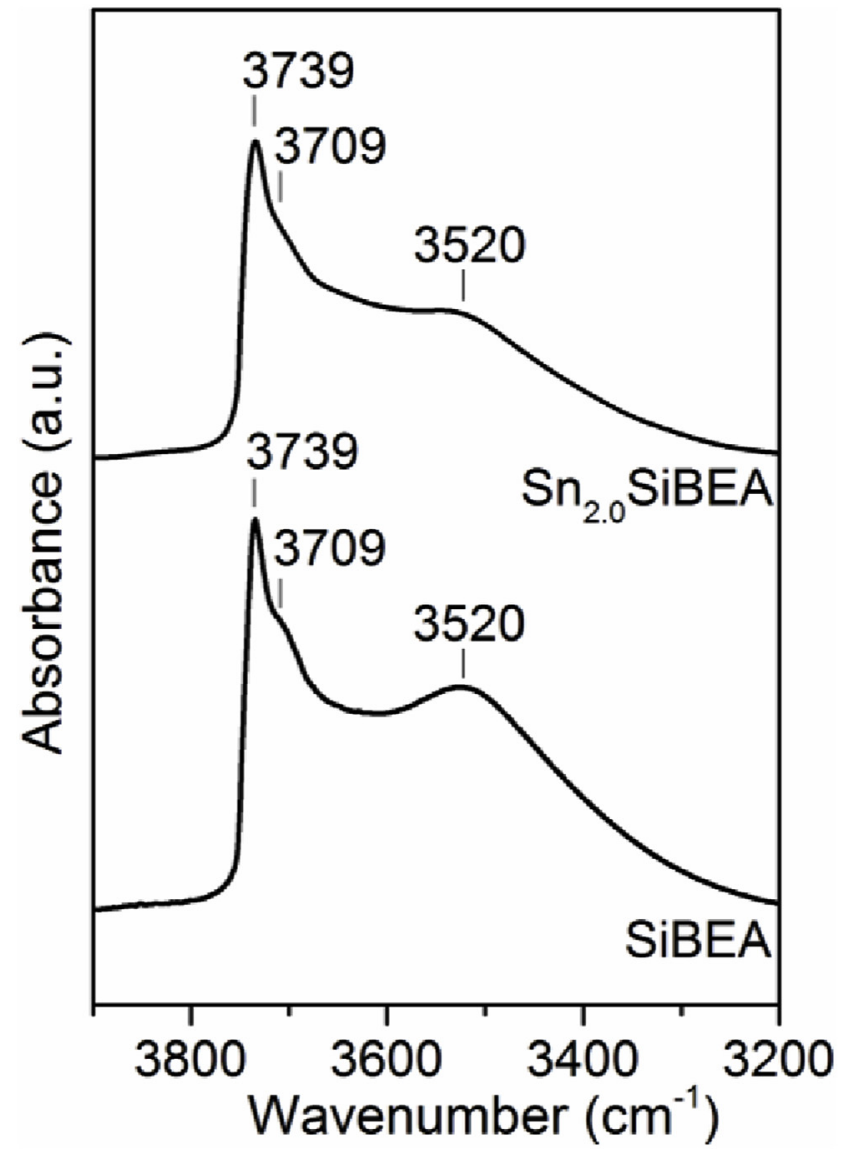

Fig. 6. IR spectra recorded at room temperature of SiBEA and $\mathrm{Sn}_{2.0} \mathrm{SiBEA}$ samples calcined at $723 \mathrm{~K}$ for $3 \mathrm{~h}$ in $\mathrm{O}_{2}(16 \mathrm{kPa})$ and then outgassed at $573 \mathrm{~K}$ $\left(10^{-3} \mathrm{~Pa}\right)$ for $1 \mathrm{~h}$.

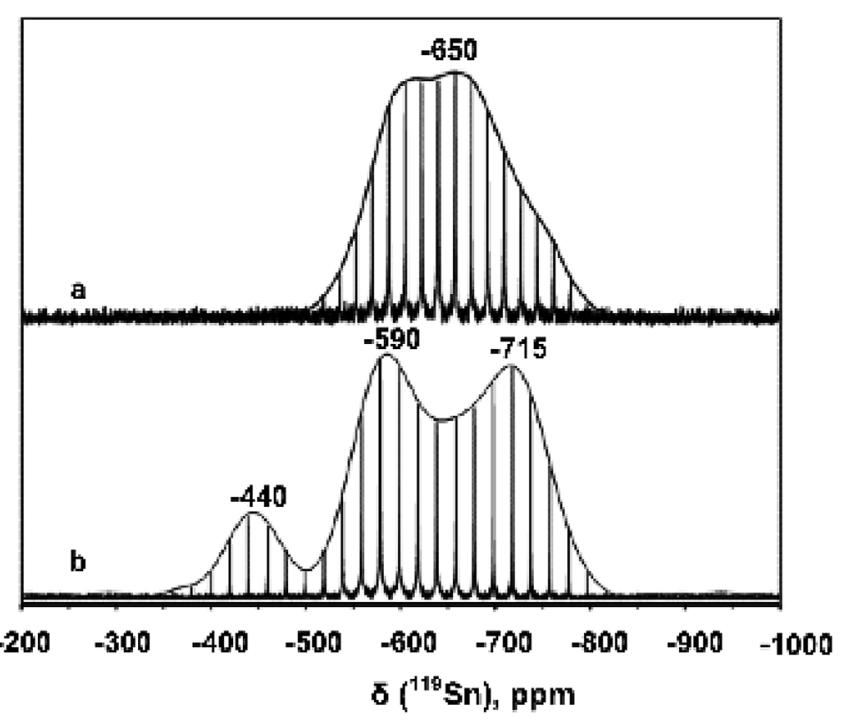

Fig. 7. ${ }^{119} \mathrm{Sn}$ static NMR spectra of $\mathrm{Sn}_{2.0} \mathrm{SiBEA}$ calcined at $773 \mathrm{~K}$ for $2 \mathrm{~h}$ and hydrated by exposure to moist air (a) and dehydrated without exposure to moist air (b) recorded at room temperature in $7 \mathrm{~mm}$ (external diameter) zirconia rotor. Chemical shifts of tin were measured by reference to $\mathrm{SnO}_{2}$ $(\delta=-604.0 \mathrm{ppm})$.

Fig. 8 shows Mössbauer spectrum of hydrated $\mathrm{Sn}_{2.0} \mathrm{SiEA}$ that consist of a single narrow quadrupole doublet with isomer shift IS close to zero corresponding to the presence of hexacoordinated Sn(IV) sites only (Table 2). In case of Sn(IV) located in the centres of undistorted 


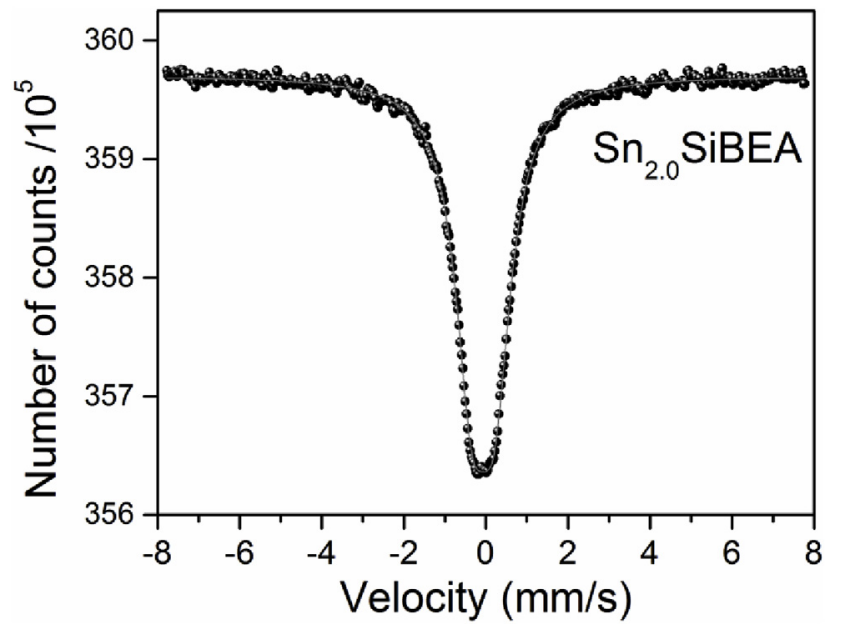

Fig. 8. ${ }^{119} \mathrm{Sn}$ Mössbauer spectrum of $\mathrm{Sn}_{2.0} \mathrm{SiBEA}$ (calcined in flowing air at $873 \mathrm{~K}$ for $2 \mathrm{~h}$ ) recorded at room temperature.

Table 2

The hyperfine parameters obtained from the Mössbauer spectroscopy measurements at room temperature.

\begin{tabular}{llll}
\hline Sample & IS (mm/s) & QS $(\mathrm{mm} / \mathrm{s})$ & w $(\mathrm{mm} / \mathrm{s})$ \\
\hline $\mathrm{Sn}_{2.0} \mathrm{SiBEA}$ & -0.07 & 0.56 & 0.50 \\
\hline
\end{tabular}

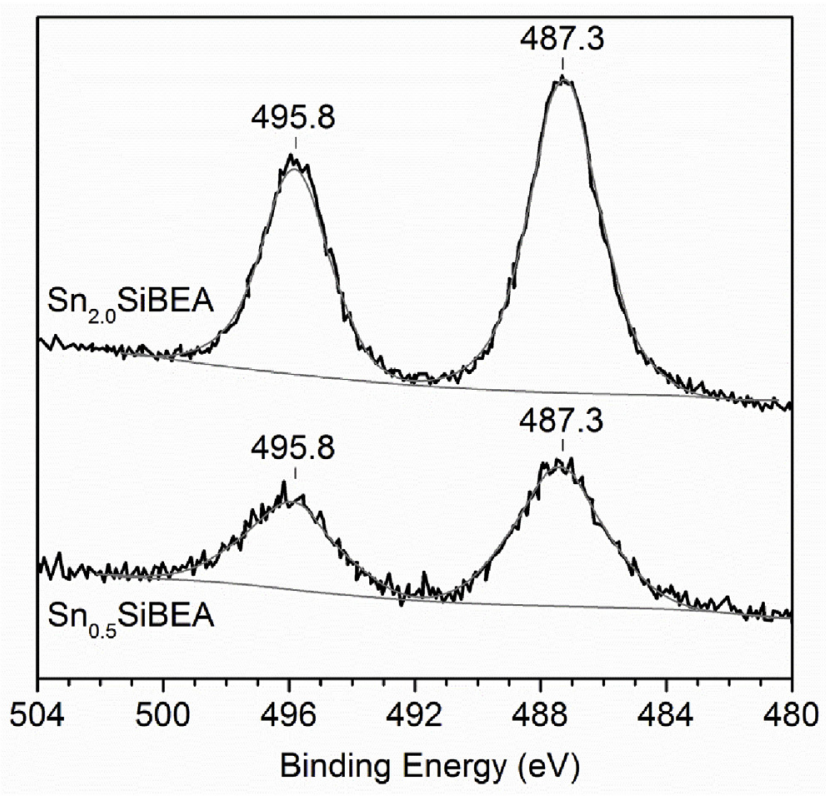

Fig. 9. Sn $3 \mathrm{~d}$ XPS spectra of $\mathrm{Sn}_{0.5} \mathrm{SiBEA}$ and $\mathrm{Sn}_{2.0} \mathrm{SiBEA}$ (calcined in flowing air at $873 \mathrm{~K}$ for $2 \mathrm{~h}$ ).

tetrahedra one can expect spectral components with lower IS $\sim-0.2 \mathrm{~mm} / \mathrm{s}$ and QS close to zero [26,27]. The hyperfine parameters of $\mathrm{Sn}_{2.0} \mathrm{SiBEA}$ quadrupole doublet are almost identical with the values observed for pure $\mathrm{SnO}_{2}$ (IS $=-0.02 \mathrm{~mm} / \mathrm{s}, \mathrm{QS}=0.49 \mathrm{~mm} / \mathrm{s}$ ) $[26,28]$. It is important to mention that some authors refer quite different hyperfine parameters for $\mathrm{SnO}_{2}$, namely $\mathrm{IS}=0.12 \mathrm{~mm} / \mathrm{s}$, $\mathrm{QS}=0.03 \mathrm{~mm} / \mathrm{s}$ [29]. Despite this divergence, above mentioned facts suggest that $\mathrm{Sn}(\mathrm{IV})$ species in hydrated $\mathrm{Sn}_{2.0} \mathrm{SiEA}$ are mainly present as octahedral tin species in extra-framework positions of the zeolite, probably as tin clusters, in line with earlier report [29]. However, the direct identification of tin as isolated mononuclear species or tin clusters from the curve-fits of Mössbauer spectra is impossible without

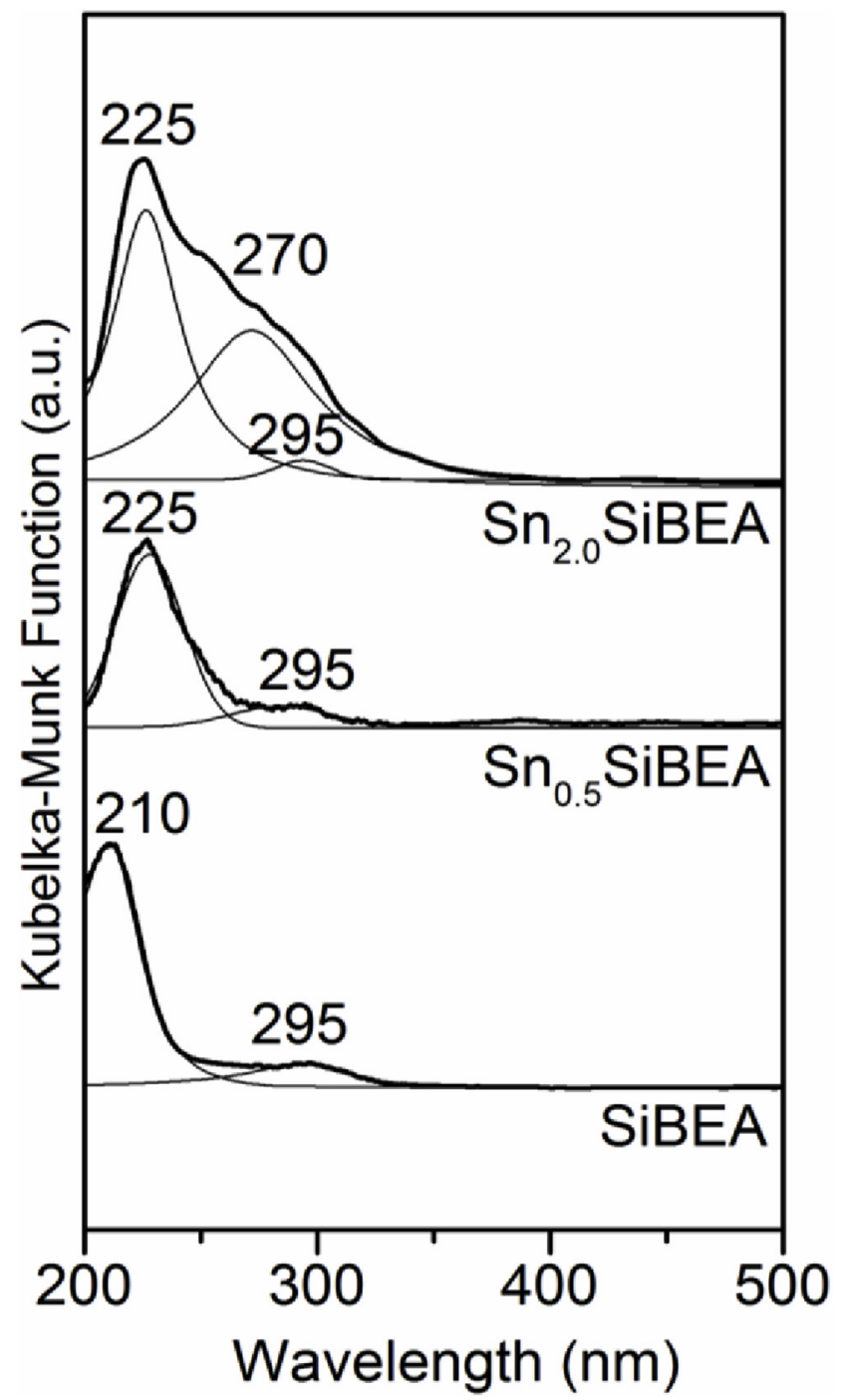

Fig. 10. DR UV-vis spectra of SiBEA, $\mathrm{Sn}_{0.5} \mathrm{SiBEA}$ and $\mathrm{Sn}_{2.0} \mathrm{SiBEA}$ (calcined in flowing air at $873 \mathrm{~K}$ for $2 \mathrm{~h}$ ) recorded at room temperature and ambient atmosphere.

further studies, e.g. $\mathrm{Sn}(\mathrm{IV}) \leftrightarrow \mathrm{Sn}(\mathrm{II})$ reversible redox process [30]. Slightly higher QS obtained in case of $\mathrm{Sn}_{2.0} \mathrm{SiBEA}$ (Table 2) suggest more distorted geometry of tin local neighbourhood. Quite reasonable values of the Mössbauer peak width of the resonance line (w) confirm high quality of the samples and its uniform structure.

The Sn $3 d$ region of the XPS spectra for $\mathrm{Sn}_{0.5} \mathrm{SiBEA}$ and $\mathrm{Sn}_{2.0} \mathrm{SiBEA}$ are depicted in Fig. 9. The Sn $3 \mathrm{~d}_{5 / 2}$ and $3 \mathrm{~d}_{3 / 2}$ peaks with binding energies of 487.3 and $495.8 \mathrm{eV}$, respectively, observed for both zeolites, confirm the presence of tetrahedrally coordinated framework Sn(IV) species $[11,31]$. In contrast, Sn(IV) species in octahedral coordination existing in the form of $\mathrm{SnO}_{2}$ nanoparticles and characterized by $3 \mathrm{~d}_{5 / 2}$ and $3 \mathrm{~d}_{3 / 2}$ signals with much lower binding energy values (486.0 and $494.4 \mathrm{eV}$ ) are not detected at the zeolite surface [11,32].

The UV-vis diffuse reflectance spectra of the zeolites are presented in Fig. 10. The spectrum of $\mathrm{Sn}_{0.5} \mathrm{SiBEA}$ shows signals at 225 and $295 \mathrm{~nm}$. The former is usually attributed to tetrahedrally coordinated Sn(IV) incorporated in the zeolite framework [31,33,34]. Usually, band of $\left(\mathrm{O}^{2-} \rightarrow \mathrm{Sn}^{4+}\right)$ charge transfer is observed at lower wavelengths $(200-210 \mathrm{~nm})$. The shift to higher wavelengths on the $\mathrm{Sn}_{0.5} \mathrm{SiBEA}$ spectrum could be caused by the formation of hydrated tin sites with higher coordination number under ambient conditions. Upon drying, the $220 \mathrm{~nm}$ tetrahedral Sn(IV) signal tend to shift to lower wavelengths 

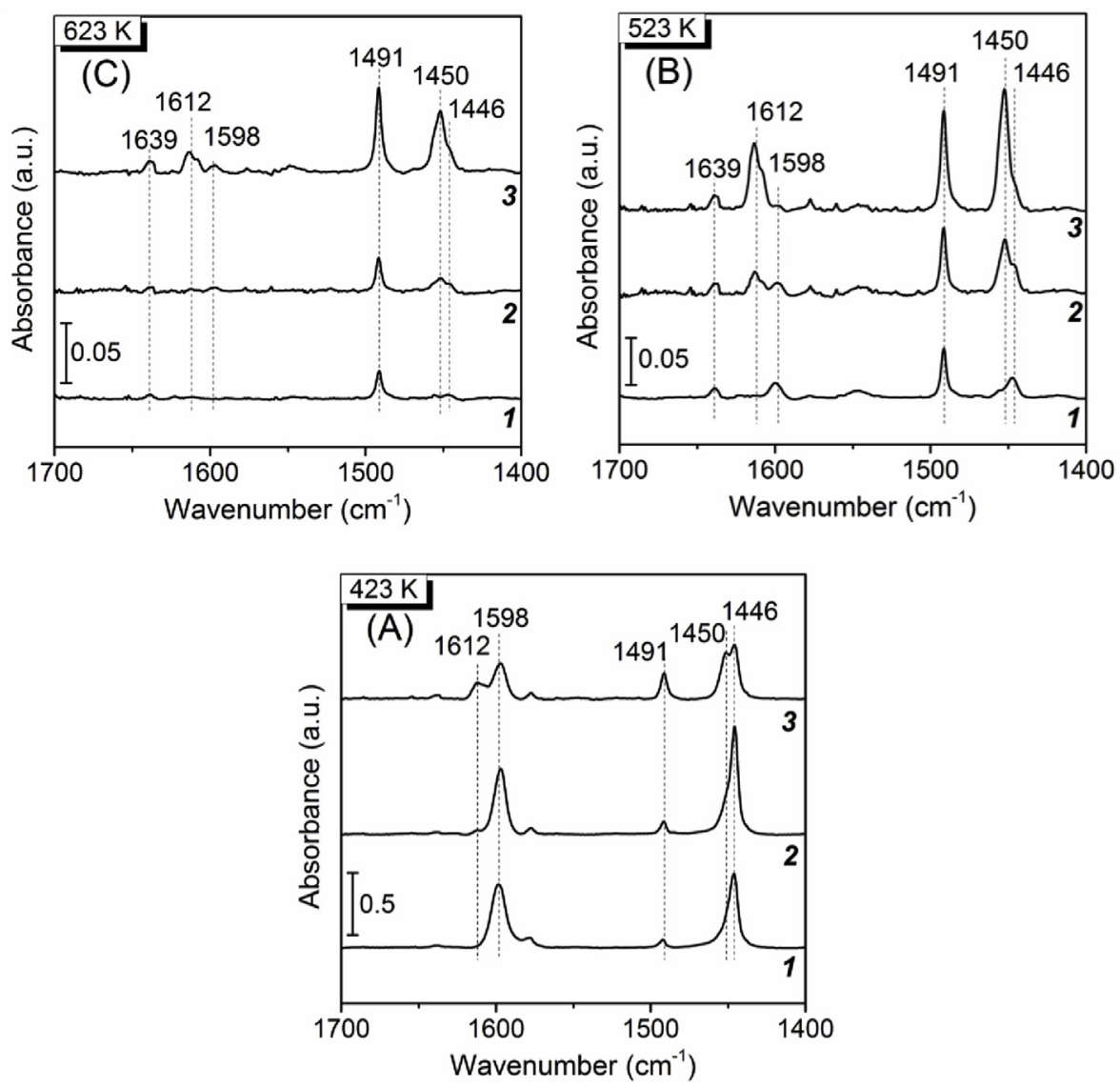

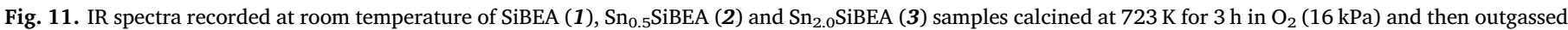
at $573 \mathrm{~K}\left(10^{-3} \mathrm{~Pa}\right)$ for $1 \mathrm{~h}$ after adsorption of pyridine $(133 \mathrm{~Pa})$ for $1 \mathrm{~h}$ at room temperature and desorption at 423,523 and $623 \mathrm{~K}$ for $1 \mathrm{~h}$.

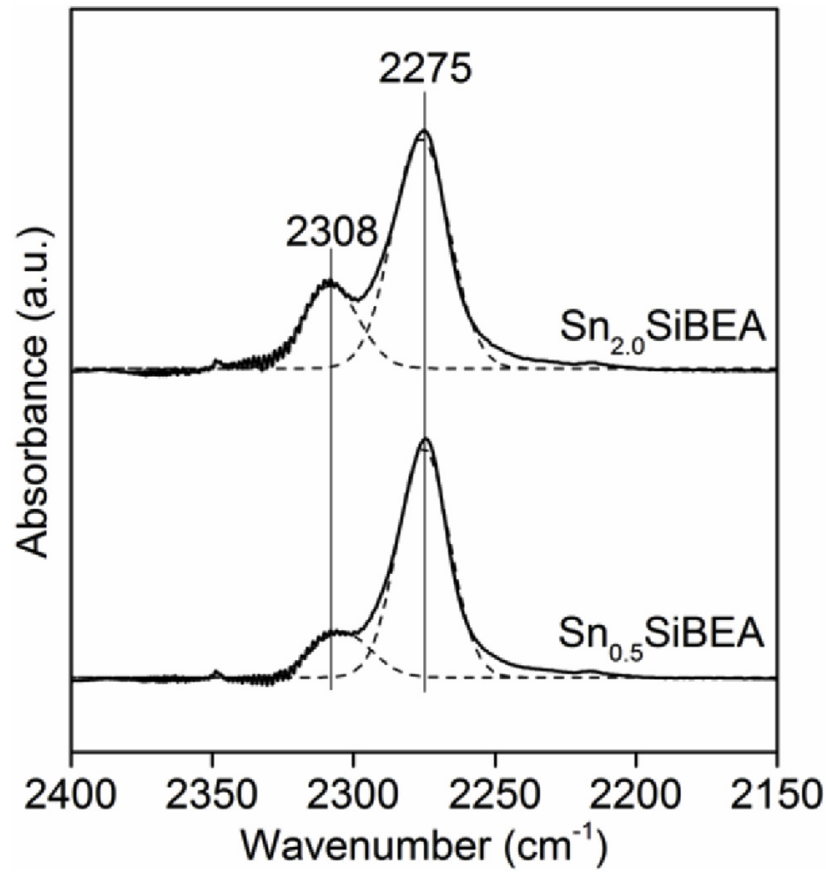

Fig. 12. IR spectra recorded at room temperature of $\mathrm{Sn}_{0.5} \mathrm{SiBEA}$ and $\mathrm{Sn}_{2.0} \mathrm{SiBEA}$ samples calcined at $723 \mathrm{~K}$ for $3 \mathrm{~h}$ in $\mathrm{O}_{2}(16 \mathrm{kPa})$ and then outgassed at $573 \mathrm{~K}$ $\left(10^{-3} \mathrm{~Pa}\right)$ for $1 \mathrm{~h}$ after adsorption of $\mathrm{CD}_{3} \mathrm{CN}$ at room temperature and then desorption at room temperature.
[31,34]. The absorption band at $295 \mathrm{~nm}$ is probably related to the charge transfer transitions in SiBEA framework. In the case of $\mathrm{Sn}_{2.0} \mathrm{SiBEA}$, the band at $225 \mathrm{~nm}$ still dominates the spectrum indicating higher amount of incorporated framework Sn(IV). Additional feature at $270 \mathrm{~nm}$ is usually assigned to octahedral tin species $[15,31,35]$ present in extra-framework positions of zeolite materials.

\subsection{IR characterization of acidic sites}

The acidic sites of the zeolites were probed with IR spectroscopy after adsorption of pyridine, deuterated acetonitrile and carbon monoxide (Figs. 11-13).

The IR difference spectra recorded after and before pyridine adsorption are shown in Fig. 11. The bands at 1446 and $1598 \mathrm{~cm}^{-1}$ correspond to physisorbed or weakly bonded pyridine, as confirmed by their almost complete disappearance at $523 \mathrm{~K}$ (Fig. $11 \mathrm{~B}$ ). The bands at 1450 and $1612 \mathrm{~cm}^{-1}$ correspond to perturbed deformation modes of pyridine bound to Lewis acidic sites. Brønsted acidic sites are almost absent (bands cantered at 1550 and $1639 \mathrm{~cm}^{-1}$ characteristic of protonated pyridine), indicating that mostly Lewis acidic sites were present on the samples. The intensity of the bands for SiBEA is much lower than for $\mathrm{Sn}_{0.5} \mathrm{SiBEA}$ and $\mathrm{Sn}_{2.0} \mathrm{SiBEA}$ (Fig. $11 \mathrm{~B}$ ) confirming that they are related to the adsorption of pyridine on tin species. The intensity of absorption bands at 1612 and $1450 \mathrm{~cm}^{-1}$ for $\mathrm{Sn}_{2.0} \mathrm{SiBEA}$ at $623 \mathrm{~K}$ is higher than for $\mathrm{Sn}_{0.5} \mathrm{SiBEA}$, suggesting higher amount of strong Lewis acidic sites formed during tin incorporation in the former sample. The concentration of Lewis acidic tin sites calculated based on the desorption of pyridine at $423 \mathrm{~K}$ is equal to $42 \mu \mathrm{mol} \mathrm{g}^{-1}$ for $\mathrm{Sn}_{0.5} \mathrm{SiBEA}$ and $95 \mu \mathrm{mol} \mathrm{g}^{-1}$ for $\mathrm{Sn}_{2.0} \mathrm{SiBEA}$.

Acetonitrile- $\mathrm{d}_{3}$ is suitable probe molecule for selective identification of tin framework Lewis acidic sites, since IR bands of $\mathrm{CD}_{3} \mathrm{CN}$ adsorbed 

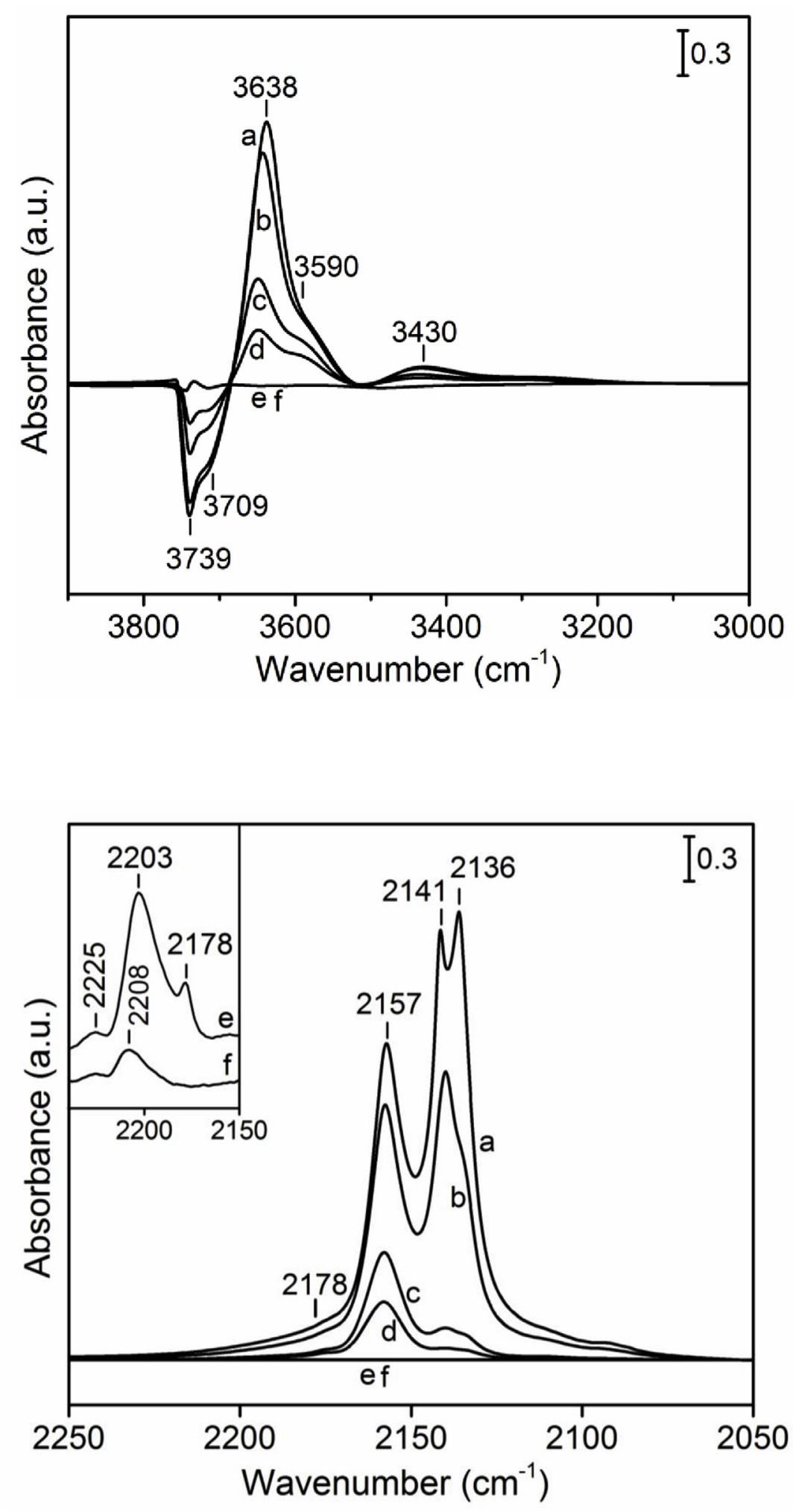

Fig. 13. IR difference spectra (OH and carbonyl stretching regions) of $\mathrm{CO}$ adsorbed at $100 \mathrm{~K}$ on $\mathrm{Sn}_{2.0} \mathrm{SiBEA}$ activated by calcination at $723 \mathrm{~K}$ for $2 \mathrm{~h}$ in flowing $2.5 \%$ $\mathrm{O}_{2} / \mathrm{Ar}$ and then outgassed at $573 \mathrm{~K}\left(10^{-3} \mathrm{~Pa}\right)$ for $1 \mathrm{~h}$ : equilibrium CO pressure of $100 \mathrm{~Pa}$ (a) and development of the spectra during evacuation at $100 \mathrm{~K}$ (b-f).

on Lewis acidic sites of $\mathrm{SnO}_{2}$ supported on silica BEA are not observed [36]. IR spectra in the $\nu(\mathrm{C} \equiv \mathrm{N})$ stretching vibration region for $\mathrm{Sn}_{0.5} \mathrm{SiBEA}$ and $\mathrm{Sn}_{2.0} \mathrm{SiBEA}$ samples are shown in Fig. 12. The band at $2275 \mathrm{~cm}^{-1}$ could be assigned to acetonitrile coordinated to silanol groups and band at $2308 \mathrm{~cm}^{-1}$ is associated with acetonitrile coordinated with LAS $[37,38]$. Usually, two types of Lewis acidic sites are detected for Sn-BEA zeolites with $2316 \mathrm{~cm}^{-1}$ and $2308 \mathrm{~cm}^{-1}$ bands of $\mathrm{CD}_{3} \mathrm{CN}$ bounded to opened and closed Lewis acidic tin sites, respectively $[17,36]$. For $\mathrm{Sn}_{2.0} \mathrm{SiBEA}$ sample one band at $2308 \mathrm{~cm}^{-1}$ (Fig. 12) correlates to ${ }^{119} \mathrm{Sn}$ MAS NMR resonance at $440 \mathrm{ppm}$ in the dehydrated sample (Fig. 7) and could be assigned to closed tin sites. Recently, the similar band at $2310 \mathrm{~cm}^{-1}$ was observed for dealuminated Sn-Beta 

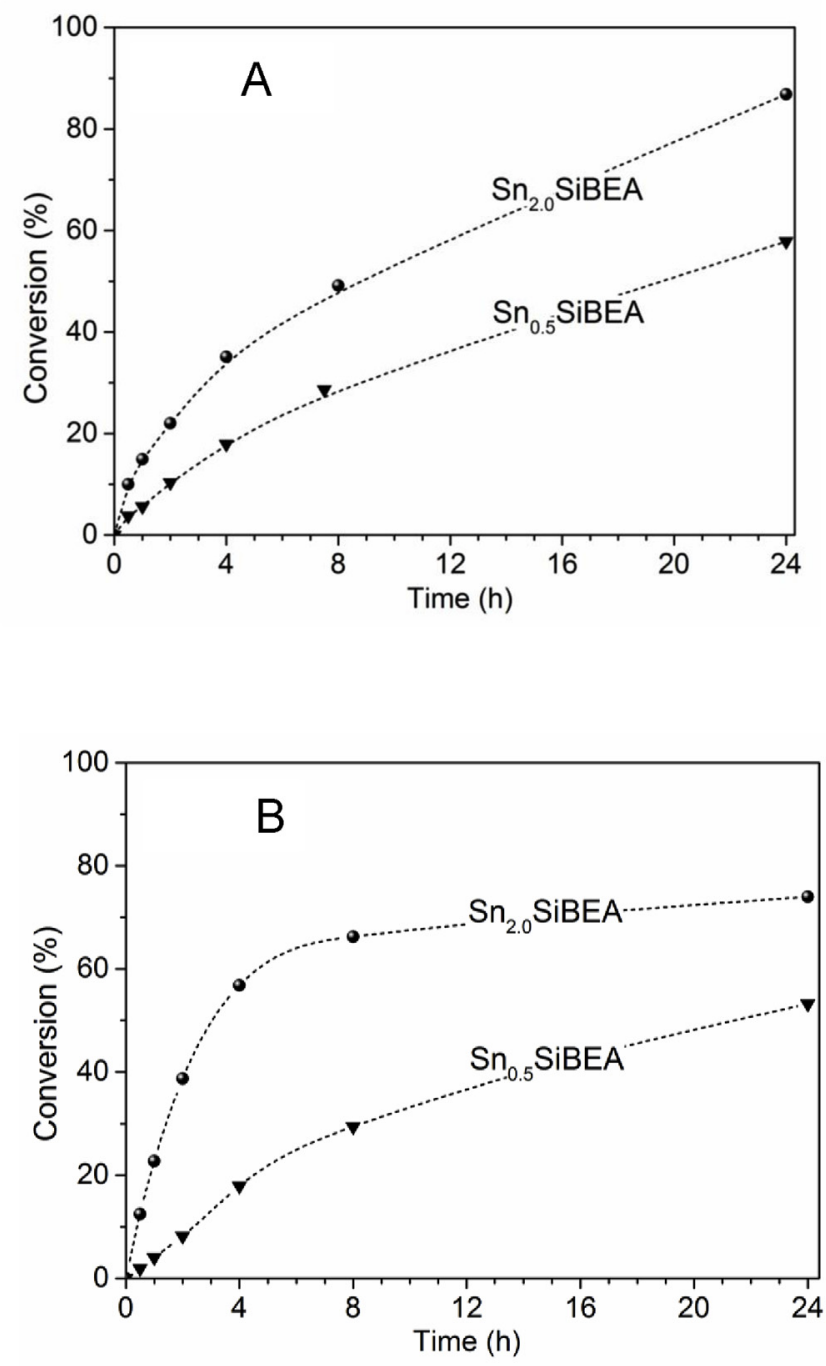

Fig. 14. Conversion of cyclohexanone to cyclohexanol in MPV reduction with 2-propanol (A) and conversion of 4-methoxybenzaldehyde to 4-methoxybenzyl sec-butyl ether (B) over $\mathrm{Sn}_{0.5} \mathrm{SiBEA}$ and $\mathrm{Sn}_{2.0} \mathrm{SiBEA}$ zeolite catalysts calcined in flowing air at $873 \mathrm{~K}$ for $2 \mathrm{~h}$.

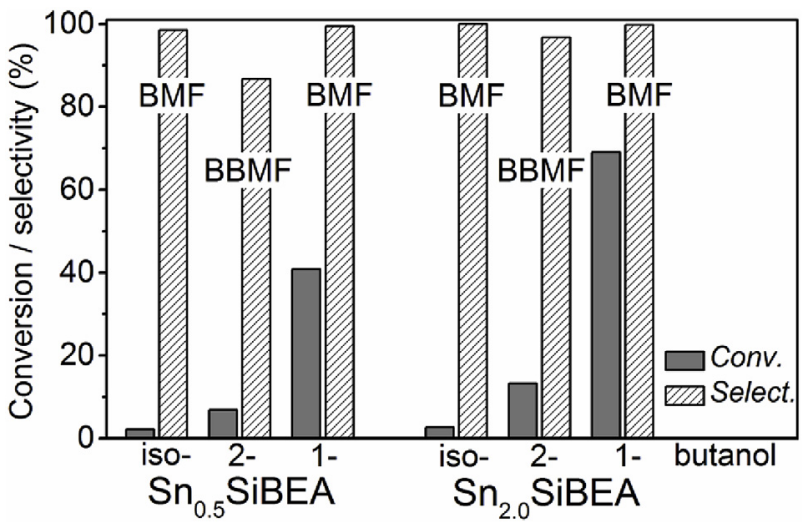

Fig. 15. Catalytic performance of the $\mathrm{Sn}_{0.5} \mathrm{SiBEA}$ and $\mathrm{Sn}_{2.0} \mathrm{SiBEA}$ zeolite catalysts (calcined in flowing air at $873 \mathrm{~K}$ for $2 \mathrm{~h}$ ) in HMF conversion with butyl alcohols (1-butanol, 2-butanol and isobutanol).

prepared by solid-state ion exchange and assigned to $\mathrm{CD}_{3} \mathrm{CN}$ coordinately bonded to isolated Sn(IV) present in the zeolite framework [2].
Table 3

Turnover frequencies and numbers for $\mathrm{Sn}_{\mathrm{x}} \mathrm{SiBEA}$ zeolites.

\begin{tabular}{|c|c|c|c|c|c|c|}
\hline TOF/TON (h-1) & \multicolumn{3}{|c|}{$\mathrm{Sn}_{0.5} \mathrm{SiBEA}$} & \multicolumn{3}{|c|}{$\mathrm{Sn}_{2.0} \mathrm{SiBEA}$} \\
\hline \multicolumn{7}{|c|}{ MPV reduction of cyclohexanone } \\
\hline $\mathrm{TOF}_{/ L A S} \mathrm{a}^{\mathrm{a}}$ & \multicolumn{3}{|l|}{25} & \multicolumn{3}{|l|}{37} \\
\hline $\mathrm{TON}_{/ L A S}^{\mathrm{b}}$ & \multicolumn{3}{|c|}{296} & \multicolumn{3}{|c|}{217} \\
\hline $\mathrm{TON}_{/ S n}{ }^{\mathrm{c}}$ & \multicolumn{3}{|l|}{299} & \multicolumn{3}{|c|}{122} \\
\hline \multicolumn{7}{|c|}{ 4-Methoxybenzaldehyde conversion } \\
\hline $\mathrm{TOF}_{/ L A S}$ & \multicolumn{3}{|l|}{24} & \multicolumn{3}{|l|}{59} \\
\hline $\mathrm{TON}_{/ L A S}$ & \multicolumn{3}{|l|}{308} & \multicolumn{3}{|l|}{192} \\
\hline $\mathrm{TON}_{/ S n}$ & \multicolumn{3}{|l|}{311} & \multicolumn{3}{|c|}{108} \\
\hline \multicolumn{7}{|l|}{ HMF conversion } \\
\hline butanol & iso- & $1-$ & $2-$ & iso- & $1-$ & $2-$ \\
\hline $\mathrm{TON}_{/ L A S}$ & 13 & 240 & 40 & 7 & 82 & 35 \\
\hline $\mathrm{TON}_{/ S n}$ & 13 & 242 & 41 & 4 & 102 & 20 \\
\hline
\end{tabular}

a Mol of substrate converted per initial hour and per mol of Lewis acidic Sn sites.

b Mol of substrate converted per mol of Lewis acidic Sn sites.

c Mol of substrate converted per mol of Sn.

Low temperature $\mathrm{CO}$ adsorption with IR control was used as probing of both Lewis and Brønsted acidic sites on $\mathrm{Sn}_{2.0} \mathrm{SiBEA}$. The IR difference spectra between ones recorded after and before $\mathrm{CO}$ adsorption at $100 \mathrm{~K}$ are given in Fig. 13. Introduction of CO (100 Pa equilibrium pressure) leads to the appearance of positive bands at 3638, 3590, 3430 and negative bands at 3739 and $3709 \mathrm{~cm}^{-1}$ in $\mathrm{OH}$ stretching range. The intensity of the positive bands quickly decreases during $\mathrm{CO}$ outgassing, while the negative bands are restored. $\mathrm{CO}$ induced $\mathrm{OH}$ bands shifts of $101 \mathrm{~cm}^{-1}$ (from 3739 to $3638 \mathrm{~cm}^{-1}$ ) and $119 \mathrm{~cm}^{-1}$ (from 3715 to $3595 \mathrm{~cm}^{-1}$ ) indicate that isolated external and terminal internal $\mathrm{Si}-\mathrm{OH}$ groups have weak acidic character. The low intensity of positive bands at $3430 \mathrm{~cm}^{-1}$ related to red shifted bands of perturbed bridging groups $[39,40]$ suggests very low amount of these hydroxyls in the zeolite. IR spectra after $\mathrm{CO}$ adsorption on $\mathrm{Sn}_{2.0} \mathrm{SiBEA}$ are similar to those obtained on SiBEA [41], indicating absence of new Brønsted acidic sites ( $\mathrm{Sn}-\mathrm{O}$ (H)-Si).

Under CO equilibrium pressure of $100 \mathrm{~Pa}$ the carbonyl bands are detected at 2178, 2157, 2141 and $2136 \mathrm{~cm}^{-1}$ (Fig. 13). The bands at 2141 and $2136 \mathrm{~cm}^{-1}$ are assigned to weakly bonded physically adsorbed CO [39] and disappear first upon outgassing. Then the band at $2157 \mathrm{~cm}^{-1}$ disappears, changing simultaneously with $3638 \mathrm{~cm}^{-1}$ band, which allows assigning the $2157 \mathrm{~cm}^{-1}$ band to CO bonded to silanol groups. Further, sample outgassing provokes disappearance of the band at $2178 \mathrm{~cm}^{-1}$, typical of CO interacting with bridging zeolite hydroxyls $\mathrm{Si}-\mathrm{O}(\mathrm{H})-\mathrm{Al}$ present as traces in the zeolite after dealumination. The low intensity band at $2225 \mathrm{~cm}^{-1}$ corresponds to $\mathrm{Al}^{3+}{ }_{-} \mathrm{CO}$ vibrations with $\mathrm{Al}$ in framework and extra-framework positions remained in the zeolite structures after dealumination. The intensity of the band at $2157 \mathrm{~cm}^{-1}$ for $\mathrm{Sn}_{2.0} \mathrm{SiBEA}$ is much lower that observed for SiBEA [41], which proves the consumption of silanol groups during incorporation of tin ions into the vacant T-atom sites of SiBEA zeolite. The significant decrease in the intensities of the silanol bands after tin incorporation in the zeolite framework is accompanied by the appearance of the band at $2203 \mathrm{~cm}^{-1}$, which remains after outgassing the sample $\left(10^{-3} \mathrm{~Pa}\right.$, see inset in Fig. 13). This absorption band could be associated with Sn-carbonyls. The bands attributed to Sn(IV)-CO were observed at $2200 \mathrm{~cm}^{-1}$ during $\mathrm{CO}$ adsorption on $\mathrm{SnO}_{2}$ sample recently [42-44]. A decrease of the band intensity together with a shift of the peak maximum to higher frequencies up to $2208 \mathrm{~cm}^{-1}$ after $30 \mathrm{~min}$ under vacuum (spectrum $\mathrm{f}$ ) shows the stability of the Sn(IV)-CO complexes and high strength of Lewis acidic sites. To our knowledge, up till now, no similar studies have been devoted to characterization of Sn-zeolites by carbon monoxide as probe molecule. 


\subsection{Catalytic properties}

Catalytic properties of the tin sites in the dealuminated Sn-BEA zeolites, prepared by two-step postsynthesis method, were tested in MPV reduction as well as with subsequent reaction of etherification, that is, conversion of (i) cyclohexanone with 2-propanol, (ii) 4-methoxybenzaldehyde with 2-butanol, and (iii) HMF with butyl alcohols (1butanol, 2-butanol or isobutanol). The results are shown in Figs. 14 and 15 , and Table 3. In the case of cyclohexanone, MPV reduction to cyclohexanol occurs (Fig. $14 \mathrm{~A}$ ) on both $\mathrm{Sn}_{2.0} \mathrm{SiBEA}$ and $\mathrm{Sn}_{0.5} \mathrm{SiBEA}$ zeolite catalysts with a higher degree of conversion in the presence of $\mathrm{Sn}_{2.0} \mathrm{SiBEA}$. For 4-methoxybenzaldehyde a tandem process was observed consisting of MPV reduction with 2-butanol to 4-methoxybenzylalcohol followed by its etherification with 2-butanol to 4methoxybenzyl sec-butyl ether. Higher conversion of aldehyde was achieved on the catalyst with higher amount of tin (Fig. 14 B). Fig. 15 shows the catalytic properties of $\mathrm{Sn}_{2.0} \mathrm{SiBEA}$ and $\mathrm{Sn}_{0.5} \mathrm{SiBEA}$ zeolites in HMF conversion with butyl alcohols. As seen the tandem process including MPV reduction of HMF to 2,5-bis(hydroxymethyl)furan with the next formation of furanic diether, 2,5-bis(butoxymethyl)furan (BBMF) was achieved only in the presence of secondary alcohol. When primary alcohols are used, the etherification of HMF by isobutanol or 1butanol takes place with formation of 5-(butoxymethyl)furfural (BMF). It is apparent that secondary alcohols are better hydrogen donors than primary alcohols [7,45].

As shown above by the pyridine adsorption with IR monitoring, $\mathrm{Sn}_{2.0} \mathrm{SiBEA}$ has higher amount of strong Lewis acidic tin sites, resulting in a higher rate of cyclohexanone and 4-methoxybenzaldehyde conversion during first hours of the reaction. TOF per Lewis acidic tin site over $\mathrm{Sn}_{2.0} \mathrm{SiBEA}$ is around two times greater than for $\mathrm{Sn}_{0.5} \mathrm{SiBEA}$ (Table 3). In spite of lower initial activity, the TON values of all studied reactions are higher for the $\mathrm{Sn}_{0.5} \mathrm{SiBEA}$ catalyst. After a while, the rate of 4-methoxybenzaldehyde reaction is slowed down over $\mathrm{Sn}_{2.0} \mathrm{SiBEA}$ and the conversion has increased only by $8 \%$ from 8 to $24 \mathrm{~h}$. This may be attributed to the adsorption of water molecules, formed during the etherification of 4-methoxybenzaldehyde with 2-butanol, on strong LAS, which causes deactivation of the catalyst. In the case of cyclohexanone, etherification does not occur and, accordingly, deactivation of the catalyst was not observed. Lower conversion of HMF with 2butanol than 1-butanol may be also caused by water deactivation of active sites for MPV reduction. More significant inhibition of transfer hydrogenation and etherification after water addition was shown for the reaction of HMF with 2-butanol than 1-butanol in the presence of Sn-Beta [7].

Practically the same values of TON per LAS and per tin content confirm that all tin is incorporated in the $\mathrm{Sn}_{0.5} \mathrm{SiBEA}$ zeolite framework and forms active sites for MPV reaction and etherification. Lower TON, $S n$ for $\mathrm{Sn}_{2.0} \mathrm{SiBEA}$ indicates that the extra-framework tin oxide species are not active in these reactions. Inactivity of extra-framework tin species was shown earlier in the reactions of sugar isomerisation and intermolecular MPV [35]. The different activity of isolated framework and extra-framework species was observed earlier for etherification of 4-methoxybenzyl alcohol with 2-butanol on Nb-containing dealuminated BEA zeolites [19]. The decrease in $\mathrm{TON}_{\text {LAS }}$ for $\mathrm{Sn}_{2.0} \mathrm{SiBEA}$ may be caused by the fact that some of the detected LAS belong to the oligomeric extra-framework tin species. In addition, steric factor due to higher amount and closer proximity of Sn(IV) active sites in the zeolite framework in the case of $\mathrm{Sn}_{2.0} \mathrm{SiBEA}$ may also be one of the factors responsible for the lack of a direct proportion between the conversion of substrates and tin content and/or LAS concentration.

\section{Conclusions}

$\mathrm{Sn}_{0.5} \mathrm{SiBEA}$ and $\mathrm{Sn}_{2.0} \mathrm{SiBEA}$ zeolites obtained by two-step postsynthesis method preserve their crystallinity and porous structure after dealumination and introduction of tin in SiBEA matrix. The consumption of Si-OH groups after their reaction with tin precursor has been monitored by MAS NMR and IR spectroscopies. The zeolite with $0.5 \mathrm{wt} \%$ of $\mathrm{Sn}\left(\mathrm{Sn}_{0.5} \mathrm{SiBEA}\right)$ contains isolated framework tetrahedral $\mathrm{Sn}$ (IV) whereas one with $2.0 \mathrm{Sn}$ wt \% $\left(\mathrm{Sn}_{2.0} \mathrm{SiBEA}\right)$ - a mixture of isolated framework tetrahedral Sn(IV) and extra-framework octahedral Sn(IV) as evidenced by ${ }^{119} \mathrm{Sn}$ NMR, ${ }^{119} \mathrm{Sn}$ Mössbauer, XPS and DR UV-vis spectroscopies.

Introduction of tin in SiBEA zeolite leads to the formation of new Lewis acidic Sn(IV) sites as shown by IR spectroscopy with adsorption of pyridine, deuterated acetonitrile and carbon monoxide.

The zeolite with greater amount of tin has higher amount of strong Lewis acidic sites, resulting in higher conversion of cyclohexanone and 4-methoxybenzaldehyde and higher activity in MPV reduction as shown by means of turnover frequency. However, when the MPV process is followed by etherification, the adsorption of water molecules on strong LAS causes catalyst deactivation.

In general, the TON value is higher for $\mathrm{Sn}_{0.5} \mathrm{SiBEA}$ zeolite catalyst in all studied reactions. Thus, the formation of extra-framework tin species leads to a decrease in the specific productivity of the catalyst, whereas isolated tetrahedral Sn(IV) incorporated in the zeolite framework form active sites for MPV reaction and etherification.

\section{Acknowledgments}

The authors gratefully acknowledge Andriy Kozytskiy for ${ }^{1} \mathrm{H}$ and ${ }^{13} \mathrm{C}$ NMR measurements, Borys Deriabkin for HPLC measurements, and Małgorzata Ruggiero for her help with BET measurements. Nataliia O. Popovych is grateful to Polish Academy of Sciences for the grant for the internship at Jerzy Haber Institute of Catalysis and Surface Chemistry.

\section{Appendix A. Supplementary data}

Supplementary data related to this article can be found at http://dx. doi.org/10.1016/j.micromeso.2018.04.026.

\section{References}

[1] A. Corma, S. Iborra, A. Velty, Chem. Rev. 107 (2007) 2411-2502.

[2] P. Wolf, C. Hammond, S. Conrad, I. Hermans, Dalton Trans. 43 (2014) 4514-4519.

[3] M. Boronat, A. Corma, M. Renz, J. Phys. Chem. B 110 (2006) 21168-21174.

[4] Y. Zhu, G.K. Chuah, S. Jaenicke, J. Catal. 241 (2006) 25-33.

[5] G.K. Chuah, S. Jaenicke, Y.Z. Zhu, S.H. Liu, Curr. Org. Chem. 10 (2006) 1639-1654.

[6] J. Jae, E. Mahmoud, R.F. Lobo, D. G. Vlachos, ChemCatChem 6 (2014) 508-513.

[7] J.D. Lewis, S. Van De Vyver, A.J. Crisci, W.R. Gunther, V.K. Michaelis, R.G. Griffin, Y. Román-Leshkov, ChemSusChem 7 (2014) 2255-2265.

[8] K. Nishide, M. Node, Chirality 14 (2002) 759-767.

[9] A. Seifert, K. Rohr, R. Mahrwald, Tetrahedron 68 (2012) 1137-1144.

[10] A. Corma, F.X. Llabrés, I. Xamena, C. Prestipino, M. Renz, S. Valencia, J. Phys. Chem. C 113 (2009) 11306-11315.

[11] B. Tang, W.L. Dai, G.J. Wu, N.J. Guan, L.D. Li, M. Hunger, ACS Catal. 4 (2014) 2801-2810.

[12] M.M. Kurmach, N.O. Popovych, P.I. Kyriienko, P.S. Yaremov, A.E. Baranchikov, O.V. Shvets, Theor. Exp. Chem. 53 (2017) 114-120.

[13] A. Corma, M.E. Domine, L. Nemeth, S. Valencia, J. Am. Chem. Soc. 124 (2002) 3194-3195.

[14] S. Dzwigaj, M.J. Peltre, P. Massiani, A. Davidson, M. Che, T. Sen, S. Sivasanker, Chem. Commun. (1998) 87-88.

[15] W.N.P. Van Der Graaff, G. Li, B. Mezari, E.A. Pidko, E.J.M. Hensen, ChemCatChem 7 (2015) 1152-1160.

[16] D.G. Rancourt, J.Y. Ping, Nucl. Instrum. Meth. Phys. Res. B 58 (1991) 85-97.

[17] J.W. Harris, M.J. Cordon, J.R. Di Iorio, J.C. Vega-Vila, F.H. Ribeiro, R. Gounder, J. Catal. 335 (2016) 141-154.

[18] T. Blasco, M.A. Camblor, A. Corma, P. Esteve, J.M. Guil, A. Mart, S. Valencia, A. Martinez, J.A. Perdigon-Melon, J. Phys. Chem. B 102 (1998) 75-88.

[19] P.I. Kyriienko, O.V. Larina, N.O. Popovych, S.O. Soloviev, Y. Millot, S. Dzwigaj, J. Mol. Catal. A. Chem. 424 (2016) 27-36.

[20] G.L. Woolery, L.B. Alemany, R.M. Dessau, A.W. Chester, Zeolites 6 (1986) 14-16.

[21] L.W. Beck, J.F. Haw, J.L. White, J. Am. Chem. Soc. 116 (1994) 9657-9661.

[22] P. Wolf, M. Valla, A.J. Rossini, A. Comas-Vives, F. Núñez-Zarur, B. Malaman, A. Lesage, L. Emsley, C. Copéret, I. Hermans, Angew. Chem. Int. Ed. 53 (2014) 10179-10183.

[23] R. Bermejo-Deval, R. Gounder, M.E. Davis, ACS Catal. 2 (2012) 2705-2713.

[24] A.V. Yakimov, Y.G. Kolyagin, S. Tolborg, P.N.R. Vennestrøm, I.I. Ivanova, J. Phys. Chem. C 120 (2016) 28083-28092. 
[25] N.K. Mal, V. Ramaswamy, P.R. Rajamohanan, A.V. Ramaswamy, Microporous Mater. 12 (1997) 331-340.

[26] K. Lazar, A.M. Sleczky, N.K. Mal, A.V. Ramaswamy, Zeolites 19 (1997) 123-127.

[27] P. Fejes, J.B. Nagy, K. Kovacs, G. Vanko, Appl. Catal. Gen. 145 (1996) 155-184.

[28] M. Casagrande, E. Moretti, L. Storaro, M. Lenarda, J. Gersich, L. Stievano, F.E. Wagner, Microporous Mesoporous Mater. 91 (2006) 261-267.

[29] P. Ferrini, J. Dijkmans, R. De Clercq, S. Van de Vyver, M. Dusselier, P.A. Jacobs, B.F. Sels, Coord. Chem. Rev. 343 (2017) 220-255.

[30] V. Ramaswamy, P. Shah, K. Lazar, A.V. Ramaswamy, Catal. Surv. Asia 12 (2008) 283-309.

[31] J. Dijkmans, M. Dusselier, D. Gabriëls, K. Houthoofd, P.C.M.M. Magusin, S. Huang, Y. Pontikes, M. Trekels, A. Vantomme, L. Giebeler, S. Oswald, B.F. Sels, ACS Catal. 5 (2015) 928-940.

[32] S. Vallejos, S. Selina, F.E. Annanouch, I. Gràcia, E. Llobet, C. Blackman, Sci. Rep. 6 (2016) 28464.

[33] S. Conrad, R. Verel, C. Hammond, P. Wolf, F. Göltl, I. Hermans, ChemCatChem 7 (2015) 3270-3278.

[34] J. Dijkmans, M. Dusselier, W. Janssens, M. Trekels, A. Vantomme, E. Breynaert, C. Kirschhock, B.F. Sels, ACS Catal. 6 (2016) 31-46.
[35] J. Dijkmans, J. Demol, K. Houthoofd, S. Huang, Y. Pontikes, B. Sels, J. Catal. 330 (2015) 545-557.

[36] M. Boronat, P. Concepción, A. Corma, M. Renz, S. Valencia, J. Catal. 234 (2005) $111-118$.

[37] B. Wichterlová, Z. Tvarůžková, Z. Sobalík, P. Sarv, Microporous Mesoporous Mater 24 (1998) 223-233.

[38] A.G. Pelmenschikov, R.A. Van Santen, J. Janchen, E. Meijer, J. Phys. Chem. 97 (1993) 11071-11074.

[39] K.I. Hadjiivanov, G.N. Vayssilov, Adv. Catal. 47 (2002) 307-511.

[40] K. Chakarova, K. Hadjiivanov, J. Phys. Chem. C 115 (2011) 4806-4817.

[41] S. Dzwigaj, Y. Millot, J.-M. Krafft, N.O. Popovych, P. Kyriienko, J. Phys. Chem. C 117 (2013) 12552-12559.

[42] N. Sergent, P. Gelin, L. Perier-Camby, H. Praliaud, G. Thomas, Phys. Chem. Chem. Phys. 4 (2002) 4802-4808.

[43] D. Amalric-Popescu, F. Bozon-Verduraz, Catal. Lett. 64 (2000) 125-128.

[44] D. Amalric-Popescu, F. Bozon-Verduraz, Catal. Today 70 (2001) 139-154.

[45] S. Song, L. Di, G. Wu, W. Dai, N. Guan, L. Li, Appl. Catal. B Environ. 205 (2017) 393-403. 